C. Kubatzki $\cdot$ M. Montoya $\cdot$ S. Rahmstorf

A. Ganopolski $\cdot$ M. Claussen

\title{
Comparison of the last interglacial climate simulated by a coupled global model of intermediate complexity and an AOGCM
}

Received: 12 August 1999 / Accepted: 1 March 2000

\begin{abstract}
The climate at the Last Interglacial Maximum (125000 years before present) is investigated with the atmosphere-ocean general circulation model ECHAM$1 /$ LSG and with the climate system model of intermediate complexity CLIMBER-2. Comparison of the results of the two models reveals broad agreement in most large-scale features, but also some discrepancies. The fast turnaround time of CLIMBER-2 permits one to perform a number of sensitivity experiments to (1) investigate the possible reasons for these differences, in particular the impact of different freshwater fluxes to the ocean, (2) analyze the sensitivity of the results to changes in the definition of the modern reference run concerning $\mathrm{CO}_{2}$ levels (preindustrial versus "present"), and (3) estimate the role of vegetation in the changed climate. Interactive vegetation turns out to be capable of modifying the initial climate signals significantly, leading especially to warmer winters in large parts of the Northern Hemisphere, as indicated by various paleodata. Differences due to changes in the atmospheric $\mathrm{CO}_{2}$ content and due to interactive vegetation are shown to be at least of the same order of magnitude as differences between the two completely different models, demonstrating the importance of careful experimental design.
\end{abstract}

\section{Introduction}

Paleoclimate simulations potentially provide both a means to test climate models under boundary conditions different from those under which models were built, and

C. Kubatzki · S. Rahmstorf · A. Ganopolski · M. Claussen Potsdam-Institute for Climate Impact Research, PO Box 6012 03, 14412 Potsdam, Germany

M. Montoya $(\square)$

Meteorologisches Institut der Universität, Bundesstrasse 55, 20146 Hamburg, Germany (now at Potsdam-Institute for Climate Impact Research) E-mail: montoya@pik-potsdam.de an understanding of the reconstructed climatic features in terms of specific physical processes. Most of these simulations have been performed with atmosphere-only general circulation models (AGCMs) (de Noblet et al. 1996; Dong et al. 1996; Hewitt and Mitchell 1996; Kutzbach and Guetter 1986; Lorenz et al. 1996; Prell and Kutzbach 1987). More recent simulations include either an interactive ocean (Hewitt and Mitchell 1998; Kutzbach and Liu 1997; Montoya et al. 1998, 2000) or interactive vegetation (Claussen and Gayler 1997; de Noblet et al. 1997; Kubatzki and Claussen 1998; Texier et al. 1997).

Comparison of the results obtained by different models shows general agreement in the reproduction of some robust features such as intensified Northern Hemisphere summer monsoon circulation during periods in which the Earth's orbital parameters result in warmer summers in the Northern Hemisphere. However, a significant number of differences can also be detected. First attempts have been made to systematically compare the results of paleoclimate simulations performed with different GCMs in the Paleoclimate Modeling Intercomparison Project (PMIP, Joussaume and Taylor 1995), and to analyze the possible reasons for the observed differences (de Noblet et al. 2000).

Paleoclimate simulations have also been run with simplified models (Berger et al. 1993; Crowley and Kim 1994; Gallée et al. 1992; Harvey 1989). These models are at most two-dimensional and lack the description of many important processes. After comparison of results from their two-dimensional energy balance model (EBM) with results of a GCM, Hyde et al. (1989) conclude that 'the EBM performs well enough to justify its use as an exploratory tool for investigating the effects of altered boundary conditions on the Earth's annual temperature cycle'. However, to give a more reliable and detailed description of past and future climates, a reasonable representation of the major components of the climate system is needed.

In this study the results of climate simulations of the last interglacial maximum (the Eemian, around 125000 
years before present, $125 \mathrm{ky}$ BP) obtained with two different models are compared. The two models are the coupled atmosphere-ocean GCM ECHAM-1/LSG and the climate system model of intermediate complexity CLIMBER-2. The term intermediate complexity refers to the fact that the CLIMBER-2 model fills the gap between GCMs and simplified models (e.g., EBMs). Models of this kind have only recently been introduced for simulations of past climates (Brovkin et al. 1999; Claussen et al. 1999; Ganopolski et al. 1998a, b). It will be shown that most of the main large-scale features of the Eemian climate simulated by the two models agree reasonably well. However, a number of disagreements is also found. The fast turnaround time of CLIMBER-2 permits the carrying out of further sensitivity studies which help to shed light on the possible reasons for these differences, in particular the role of different freshwater fluxes into the ocean. In addition, differences resulting from the choice of the atmospheric $\mathrm{CO}_{2}$ level in the modern reference run (280 instead of $346 \mathrm{ppmv}$, Sect. 4) are investigated with this model, as well as the importance of interactive vegetation. In this way, CLIMBER-2 is introduced as a fast but still rather complex model which can be used to extend the knowledge derived from simulations with more sophisticated GCMs and to give hints for the direction of further investigations.

The work is organized as follows: Sect. 2 describes the two climate models used in this study and the experimental set-ups for each model. In Sect. 3 the simulated responses to the altered radiative forcing are compared. Section 4 describes the different climate sensitivity experiments carried out with CLIMBER-2. Vegetation feedbacks are analyzed in terms of amplification factors. Finally, Sect. 5 summarizes the main conclusions and discusses the results.

\section{The models and experimental setups}

\subsection{ECHAM-1/LSG}

The GCM used for the present study is the ECHAM-1 T21/LSG coupled ocean-atmosphere GCM (Cubasch et al. 1992). The atmospheric component (ECHAM-1) (Roeckner et al. 1992) is a spectral model with a horizontal resolution T21 $\left(5.6^{\circ} \times 5.6^{\circ}\right)$ and 19 levels in the vertical. It uses a semi-implicit scheme with a time step of 40 minutes. The prognostic variables are vorticity, divergence, temperature, surface pressure, water vapor and cloud water. Subgrid scale processes are parameterized. The diurnal radiation cycle is included. The runoff into the ocean is calculated using a simple surface hydrology model. In contrast to CLIMBER-2 (Sect. 2b) no interactive vegetation component is available, hence characteristics which would vary according to different vegetation types, such as roughness length or albedo over land, are prescribed to their present values.

The oceanic component is the Large-Scale Geostrophic (LSG) model (Maier-Reimer et al. 1993) which is based on an approximation of the primitive equations appropriate for large-scale geostrophic motion (the nonlinear advection of momentum is neglected). It has a horizontal E-grid with a similar resolution to that of ECHAM1-T21 and 11 variably spaced levels in the vertical. It uses an implicit time-integration scheme with a time step of 30 days, which in the coupled model is reduced to 1 day for the computation of sea-ice, temperature and salinity at the uppermost two layers. It includes a simple thermodynamic sea-ice model without horizontal transport.

The atmospheric and oceanic models are integrated synchronously and coupled by the air-sea fluxes of momentum, heat and fresh water. In order to minimize a climate drift of the coupled system away from the climatologies simulated by the uncoupled models, a correction (Sausen et al. 1988) is applied to the heat, freshwater and momentum fluxes entering the ocean. The correction is constant in time except for the seasonal cycle. The heat flux correction reaches its maxima at the sea-ice edges, where its magnitude is of the order of or even exceeds the baseline fluxes as calculated in the atmosphere. A similar problem is encountered for the freshwater flux correction. A more detailed description of the flux correction fields and associated problems can be found in Gates et al. (1993) and Rahmstorf (1995).

The ECHAM-1/LSG model was validated for a $\mathrm{CO}_{2}$ concentration of 330 ppmv in one of the few coupled runs of millennial duration performed up to now with modern boundary conditions (von Storch et al. 1997), which constitutes the control run for this model, and has been used in several climate change experiments (Bakan et al. 1991; Cubasch et al. 1992, 1994). The sensitivity of the model to a doubling of $\mathrm{CO}_{2}$ is $2.6^{\circ} \mathrm{C}$. The reader is referred to von Storch et al. (1997) for a thorough description of the control run.

\subsection{CLIMBER-2}

The global climate system model CLIMBER (for CLIMate and BiosphERe) was developed at the Potsdam-Institute for Climate Impact Research especially for long-term climate simulations. A detailed description of the model can be found in Petoukhov et al. (2000).

CLIMBER-2 has a resolution of $10^{\circ}$ in latitude and approximately $51^{\circ}$ in longitude (except for the ocean module). It consists of different modules. The atmospheric module is a 2.5-dimensional statistical-dynamical model which includes many of the processes that are also described by more sophisticated GCMs. In contrast to GCMs, CLIMBER-2 does not resolve individual synoptic scale systems, but rather predicts the statistical characteristics connected with ensembles of these systems. However, the large-scale circulation (e.g., the monsoons, jet streams, Hadley circulation) and the main high- and low-pressure areas are explicitly resolved. The model is based on the assumption of a universal vertical structure of temperature and humidity in the atmosphere. This allows one to reduce the 3-dimensional description to a set of 2-dimensional, vertically averaged prognostic equations for temperature and humidity. The 3-dimensional fields which are needed for the calculation of dynamics and of radiative fluxes can than be restored by using the vertical profiles. The atmospheric circulation as well as energy and water fluxes are computed at 10 pressure levels, while long-wave radiation is calculated using 16 levels. An explicit integration scheme is used, in general the time step is one day.

The terrestrial vegetation module is the VEgetation COntinuous DEscription model VECODE (Brovkin et al. 1997). Potential vegetation is presented as a mixture of trees, grass, and desert (bare soil). The fraction of each within a grid cell is a continuous function of the growing degree days and the annual precipitation. Thus, changes in vegetation fractions can be interpreted as shifts in vegetation zones.

The ocean module is based on the model of Stocker et al. (1992) and describes the zonally averaged characteristics for the three separate ocean basins (Atlantic, Pacific, and Indian) with a latitudinal resolution of $10^{\circ}$. It has 11 levels in the vertical including an upper mixed layer of $50 \mathrm{~m}$ thickness. An explicit scheme is used, the time step is 10 days. Temperature, salinity, and vertical and meridional velocity are calculated within each basin; at the circumpolar oceans, where the basins are connected, zonal velocities are determined in addition. The model includes a simple thermodynamic sea-ice model predicting the sea-ice fraction and thickness for each grid box with advection and diffusion of ice. 
The modules are coupled by the fluxes of energy, momentum, and water via an interface which is a strongly modified version of the Biosphere-Atmosphere Transfer (BATS) Scheme (Dickinson et al. 1986). Each model grid box consists of one or several of six surface types (open water, sea ice, trees, grass, bare soil, and glaciers). For each type sub-, near- and surface characteristics as well as surface fluxes, are calculated separately taking the different surface properties like albedo or roughness length into account. Soil processes are described within a two-layer soil model.

The atmospheric module of CLIMBER-2 can be run with prescribed ocean and vegetation characteristics, or alternatively coupled to the ocean module, the vegetation module, or both $(A$, $A O, A V$ and $A O V$ simulations respectively, see Sect. 4). None of the coupled model versions employ any type of flux adjustment.

CLIMBER-2 is validated for preindustrial boundary conditions (modern insolation and a $\mathrm{CO}_{2}$ concentration of $280 \mathrm{ppmv}$ ). CLIMBER-2 performs reasonably for modern climate and its $\mathrm{CO}_{2}$ sensitivity is similar to that of coupled GCMs $\left(3.0^{\circ} \mathrm{C}\right.$ for a doubling of $\mathrm{CO}_{2}$, see also results of transient greenhouse warming experiments by Rahmstorf and Ganopolski 1999). Details of the validation are described elsewhere (Petoukhov et al. 2000; Ganopolski et al. 1998a).

\subsection{Experimental setups}

Two experiments were performed with each of the models: a control run representing the present climate and an equilibrium Eemian run representing the climate of the last interglacial maximum as obtained by changing the external forcing as explained below. ECHAM-1/LSG was integrated for 510 years in the Eemian run, starting at year 600 of the 1260 -year control run (von Storch et al. 1997). CLIMBER-2 (in its coupled atmosphere-ocean version, $A O$ ) was integrated for 4000 years in both runs. Vegetation was fixed to its modern state in both runs.

The external forcing of the Eemian and control runs differs in two ways (Table 1): the $\mathrm{CO}_{2}$ concentration and the incoming solar radiation. The $\mathrm{CO}_{2}$ levels in the runs performed with ECHAM-1/ LSG were set to 267 ppmv (Barnola et al. 1987) and 330 ppmv in the Eemian and control run, respectively. In the runs with CLIMBER-2, 280 ppmv and 346 ppmv were used instead, which results in approximately the same $\mathrm{CO}_{2}$ forcing for the difference at the Eemian relative to the control run as in the ECHAM-1/LSG model, as the dependence of radiative forcing on $\mathrm{CO}_{2}$ concentration is logarithmic.

The incoming solar radiation at the top of the atmosphere was changed by setting the Earth's orbital parameters to their values at 125 ky BP (Berger 1978): the eccentricity of the Earth's orbit was

Table 1 Boundary conditions for the model intercomparison. For $\mathrm{CO}_{2}$ conditions, the first number gives the values used in ECHAM$1 / \mathrm{LSG}$, the second those used in CLIMBER-2

\begin{tabular}{lllll}
\hline & $\begin{array}{l}\mathrm{CO}_{2} \\
(\mathrm{ppm})\end{array}$ & $\begin{array}{l}\text { Eccentricity } \\
\text { (degrees) }\end{array}$ & $\begin{array}{l}\text { Obliquity } \\
\text { (degrees) }\end{array}$ & $\begin{array}{l}\text { Perihelion } \\
\text { (degrees) }\end{array}$ \\
\hline Present & $330 / 346$ & 0.017 & 23.45 & 282.16 \\
$125 \mathrm{ky} \mathrm{BP}$ & $267 / 280$ & 0.040 & 23.79 & 127.27 \\
\hline
\end{tabular}

greater, obliquity was slightly greater, and, with the vernal equinox fixed at March 21st for all experiments, perihelion took place in northern summer (July) instead of in northern winter (January), as in the present. The effect of the altered orbital parameters was increased (reduced) insolation at the top of the atmosphere at all latitudes during northern summer (winter) at $125 \mathrm{ky}$ BP with respect to present, that is, the seasonal cycle of insolation was amplified (attenuated) at all latitudes in the Northern (Southern) Hemisphere (Fig. 1).

\section{Comparison of mean simulated fields}

Differences in the summer, winter and annual mean anomaly fields (Eemian minus control run) as simulated by CLIMBER-2 and by ECHAM-1/LSG, averaged over the last several hundred years, are compared. Since the effect on the calendar of the variation of the orbital parameters (Joussaume and Braconnot 1997) is small in the solsticial seasonal mean fields (Montoya et al. 1998), northern summer and winter are, as usually, defined as June-August (JJA), and December-February (DJF), respectively. The focus is on the comparison of model results, not so much on the description of results for the Eemian simulations themselves, as those can be found elsewhere for the ECHAM-1/LSG model (Montoya et al. 2000). To this end, results with ECHAM-1/LSG were interpreted in terms of CLIMBER-2 resolution.

\subsection{Near surface temperature}

The near surface temperature responses simulated by the two models (Fig. 2a-d) broadly agree, both in JJA and DJF. The main common features include: (1) in JJA (DJF) strong warming (cooling) over northern and southern (sub-)tropical landmasses, with a weaker response over the ocean; (2) a reduced meridional temperature gradient in the Northern Hemisphere; (3) high northern latitude warming throughout most of the year. The latter is a result of the decreased sea-ice area due to the enhanced summer insolation at these latitudes and the positive sea ice albedo-temperature feedback.

In JJA, the agreement of the models is best over the Northern Hemisphere (Fig. 2a, c), which is consistent with the view that summer temperatures are essentially determined by insolation. Discrepancy is found over Antarctica and the Southern Ocean, where CLIMBER-2 simulates a much stronger cooling than ECHAM-1/ LSG throughout the year (corresponding to a much
Fig. 1 Difference in zonally averaged incoming solar radiation (125000 years ago minus present) as a function of latitude and time $\left(\mathrm{W} \mathrm{m}^{-2}\right)$

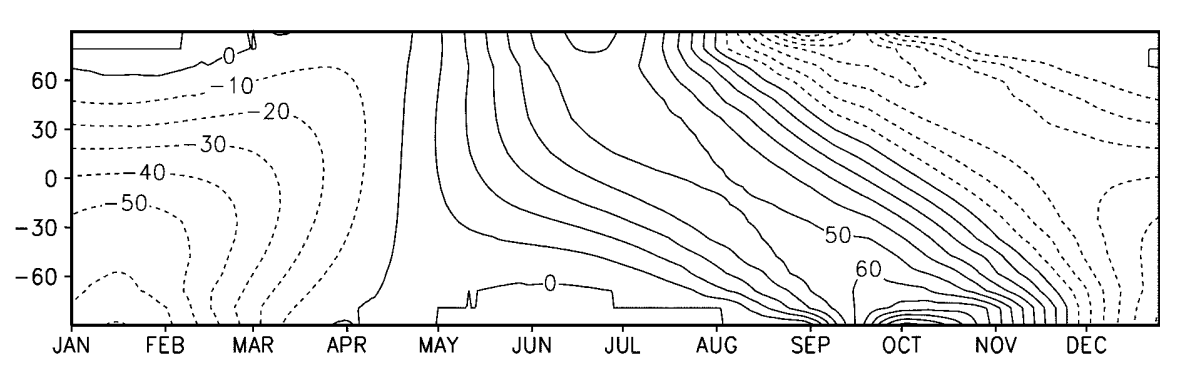


a T2 JJA ECHAM-1/LSG (C)

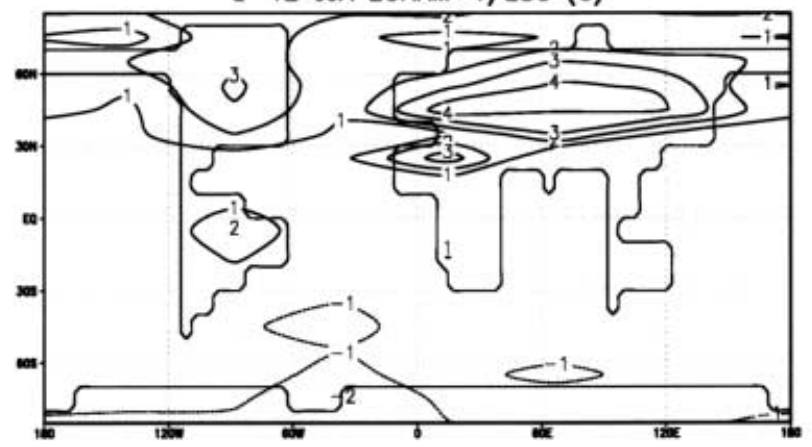

b T2 DJF ECHAM-1/LSG (C)

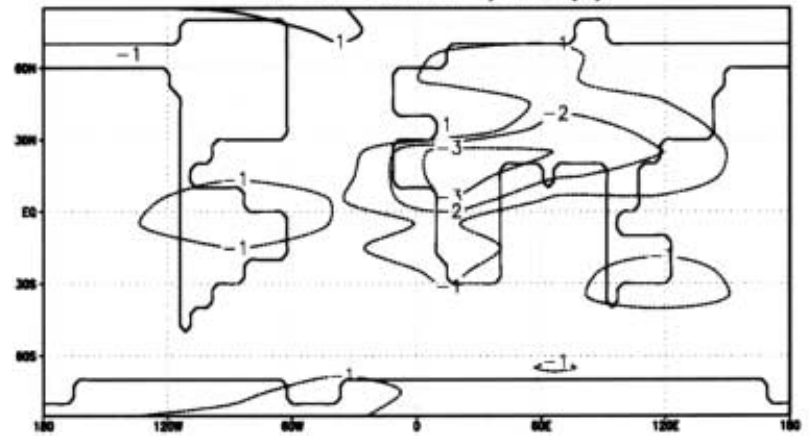

c T2 JJA CLIMBER-2 (C)

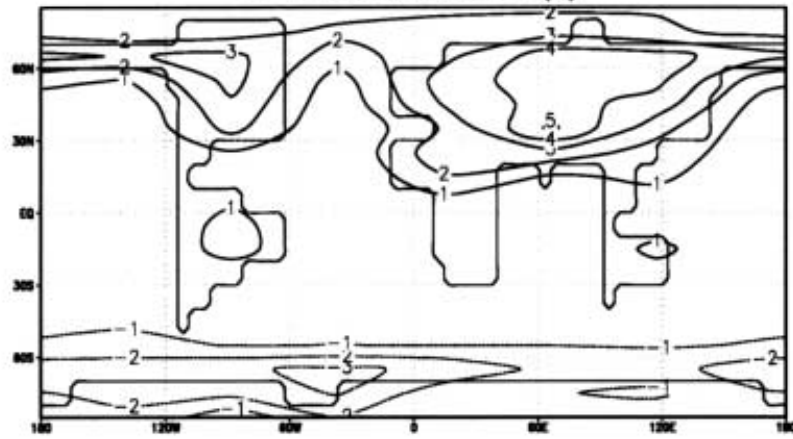

d T2 DJF CLIMBER-2 (C)

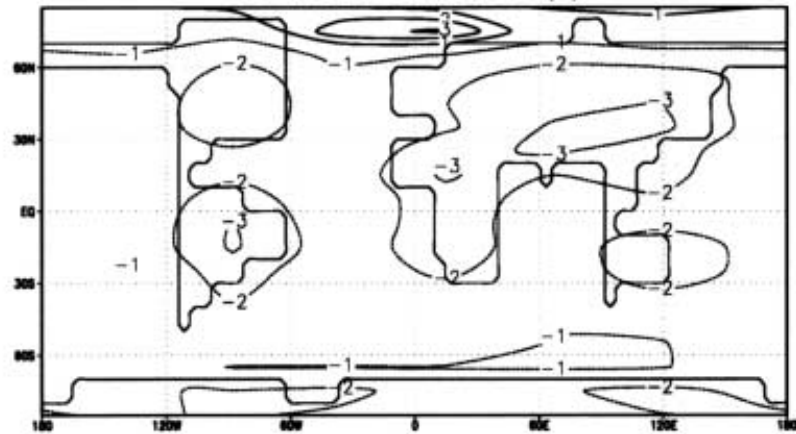

Fig. 2a-d Mean difference (Eemian minus control) in near surface temperature for a JJA and b DJF, as simulated by ECHAM-1/LSG and c JJA and d DJF, as simulated by CLIMBER-2 (contour intervals all $1{ }^{\circ} \mathrm{C}$ )

larger increase in sea-ice area, not shown). However, due to deficiencies in the sea-ice simulation, this area is a problematic one for ECHAM-1/LSG, and results should be considered with caution (Cubasch et al. 1994).

In DJF (Fig. 2b, d), dynamical processes play a more important role in determining Northern Hemisphere temperatures. Thus, disagreement in the thermal responses in this area can be partially attributed to differences in how the two models simulate the latter processes. Essentially, CLIMBER-2 shows an overall stronger winter cooling than ECHAM-1/LSG, especially at mid and high northern latitudes. Large ocean areas in these latitudes show a cooling in CLIMBER-2 but a warming in ECHAM-1/LSG. A first hypothesis is that this might be related both to the differences in the strength of the mean ocean circulation and in its response, as shown by the two models (Sect. 3.5).

In the annual mean (not shown), both models simulate changes in the near surface temperature below $1{ }^{\circ} \mathrm{C}$ almost everywhere except for high latitudes. The globally averaged changes as simulated by CLIMBER- 2 and ECHAM-1/LSG are -0.8 and $-0.3{ }^{\circ} \mathrm{C}$, respectively (Table 2).

\subsection{Sea level pressure}

The sea level pressure (SLP) response simulated by both models (not shown) over the continents generally reflects the thermally direct response to the temperature

Table 2 Annually (JJA) averaged differences in temperature (in ${ }^{\circ} \mathrm{C}$ ) and precipitation (in $\mathrm{mm} \mathrm{day}^{-1}$ ) for selected areas

\begin{tabular}{|c|c|c|c|c|c|c|}
\hline & \multicolumn{3}{|l|}{$\mathrm{T}\left({ }^{\circ} \mathrm{C}\right)$} & \multicolumn{3}{|c|}{ Precipitation $\left(\mathrm{mm}\right.$ day $\left.^{-1}\right)$} \\
\hline & $\mathrm{NH}_{\mathrm{L}}$ & NH & SH & $\mathrm{NH}_{\mathrm{L}}$ & $\mathrm{SH}_{\mathrm{L}}$ & $\mathrm{N}^{-\mathrm{AFR}_{\mathrm{L}}}$ \\
\hline \multicolumn{7}{|c|}{ Eemian-Present ECHAM-1/LSG and CLIMBER-2 $\left(\mathrm{CO}_{2}\right.$ from Table 1$)$} \\
\hline ECHAM-1/LSG & $-0.3(2.2)$ & $-0.1(1.1)$ & $-0.5(0.3)$ & $0.04(0.23)$ & $-0.19(-0.05)$ & $0.17(0.88)$ \\
\hline CLIMBER-2 & $-0.7(2.9)$ & $-0.6(1.5)$ & $-1.0(-0.4)$ & $0.07(0.45)$ & $-0.18(0.08)$ & $0.38(1.33)$ \\
\hline \multicolumn{7}{|c|}{ Eemian-Preindustrial CLIMBER-2 $\left(\mathrm{CO}_{2}=280 \mathrm{ppmv}\right)$} \\
\hline$A$ & $0.4(4.5)$ & $0.3(2.6)$ & $0.1(0.9)$ & $0.19(0.63)$ & $-0.07(0.18)$ & $0.46(1.59)$ \\
\hline$A O$ & $0.6(4.3)$ & $0.5(2.6)$ & $0.3(0.9)$ & $0.19(0.61)$ & $-0.03(0.17)$ & $0.46(1.56)$ \\
\hline$A V$ & $0.8(5.2)$ & $0.5(3.0)$ & $0.1(0.9)$ & $0.33(0.94)$ & $-0.07(0.18)$ & $1.09(3.14)$ \\
\hline$A O V$ & $1.7(5.7)$ & $1.4(3.6)$ & $0.8(1.6)$ & $0.41(1.05)$ & $0.04(0.22)$ & $1.22(3.40)$ \\
\hline
\end{tabular}

NH: Northern Hemisphere; SH: Southern Hemisphere; N-AFR: North Africa between 10 and $30^{\circ}$ N; subscript L indicates averages over land only 
changes, with decreased SLP over the warmer northern landmasses in JJA and increased SLP over the colder subtropical landmasses in DJF. The opposite responses of the models at high northern latitudes are due to the different temperature response patterns in the two models.

The agreement over the oceans is less satisfactory. In CLIMBER-2, SLP changes over land in the Northern Hemisphere are compensated through enhanced subsidence/uplift over the surrounding oceans, while ECHAM-1/LSG shows a strong interhemispheric mass transport. Nevertheless, both models agree in reflecting a generally enhanced land-sea SLP contrast at the Eemian with respect to the control runs.

\subsection{Precipitation}

Significant quantitative differences in the changes in precipitation as simulated by the two models reflect in part the effect of orography, which is much coarser in CLIMBER-2 than in ECHAM-1/LSG. However, their large-scale precipitation responses (Fig. 3a-d) show a qualitative agreement: (1) increase of precipitation is found over North Africa and South Asia in JJA consistent with an intensification of the northern summer monsoon. The latter is caused by the enhanced land-sea pressure contrast, which strengthens the onshore inflow and moisture transport into land; and (2) a decrease is found over South America, South Africa, and Australia in DJF, accompanied by an increase over the Indian Ocean. This reflects an attenuation of the summer monsoon circulation in the Southern Hemisphere. The changes in the monsoon circulations determine the zonally averaged over land (Fig. 4) and global pictures which show a satisfactory agreement between the two models. The main qualitative difference is the increase of precipitation in northern mid-latitudes in JJA in CLIMBER-2 which is not found in ECHAM-1/LSG.

\subsection{Atmospheric circulation}

Qualitatively, changes in the zonally averaged zonal wind velocity simulated by the two models (Fig. 5a-d) agree better in JJA than in DJF. Both models show an intensification of the tropical easterly jet in JJA connected with the changes in monsoon circulation (see Sect. 3.3), and a decrease in the intensity of the zonally averaged westerly flow at all levels, both in DJF and JJA. The latter is consistent with the reduction of the thermal wind caused by the decrease in the meridional temperature gradient at all levels throughout the troposphere. The disagreements observed in DJF can be explained as follows: CLIMBER-2 shows a warming only over the high northern latitude, sea-ice covered regions, whereas to the south of about $60^{\circ} \mathrm{N}$ a temperature decrease of about $2{ }^{\circ} \mathrm{C}$ is found. Thus, an abrupt decrease in temperature gradient and hence in the zonal circulation take place in this area. In ECHAM-1/LSG,
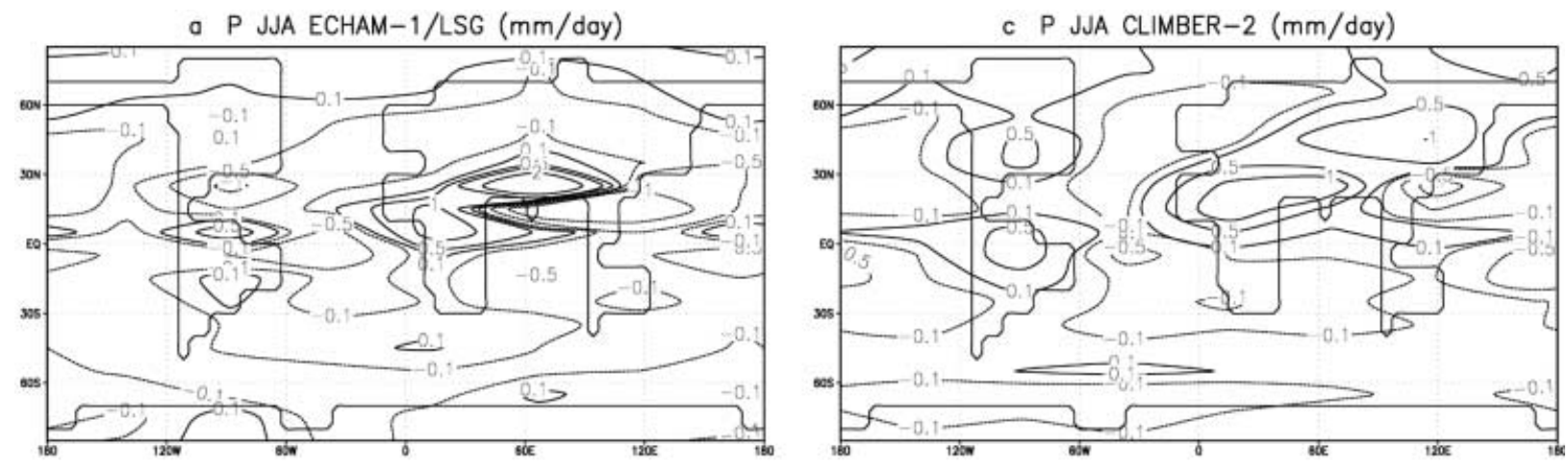

b P DJF ECHAM-1/LSG ( $\mathrm{mm} /$ day)

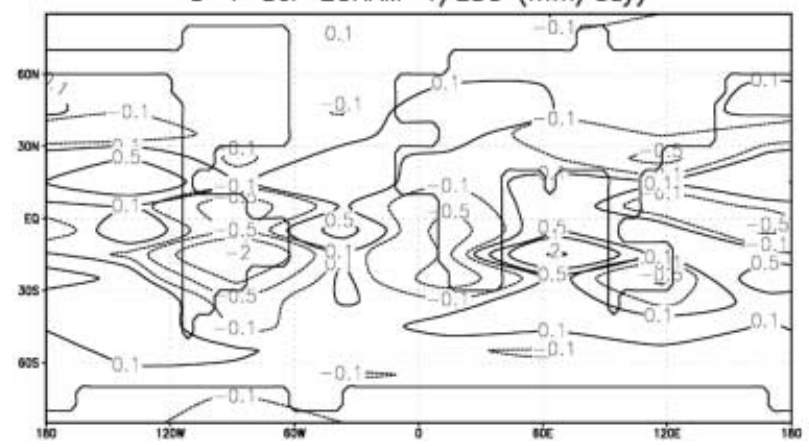

d P DJF CLIMBER-2 ( $\mathrm{mm} /$ day)

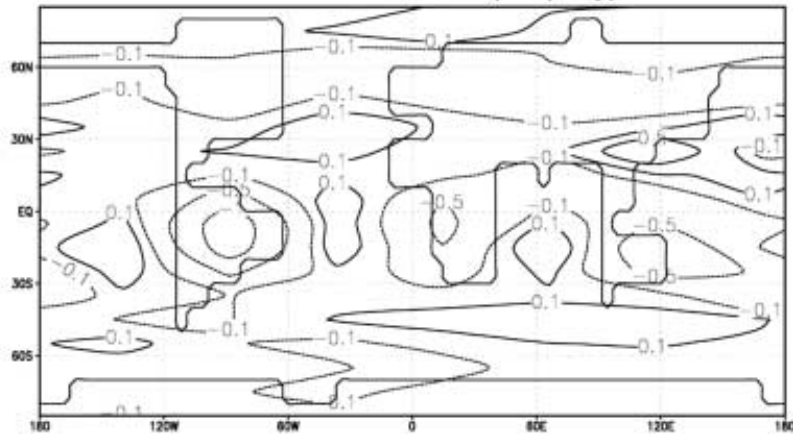

Fig. 3a-d Mean difference (Eemian minus control) in total precipitation for a JJA and b DJF, as simulated by ECHAM-1/LSG and $\mathbf{c}$ JJA and d DJF, as simulated by CLIMBER-2 (contour intervals at $-1,-0.5,-0.1,0.1,0.5,1,2 \mathrm{~mm} \mathrm{day}^{-1}$ ) 


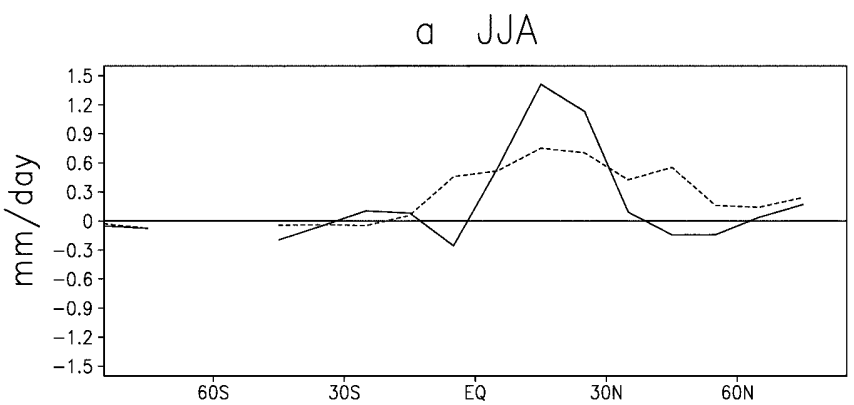

b DJF

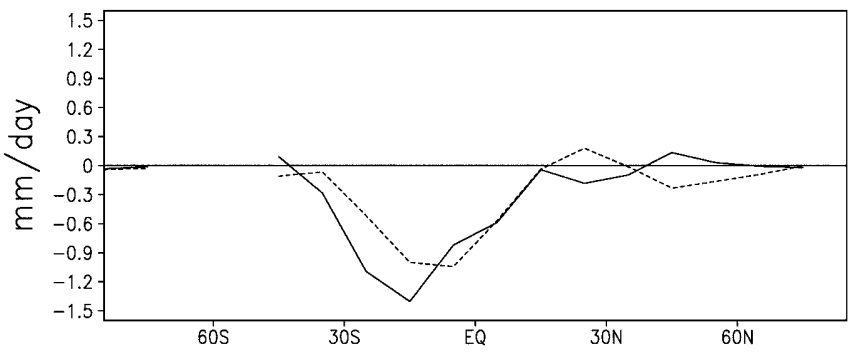

c Annual Mean

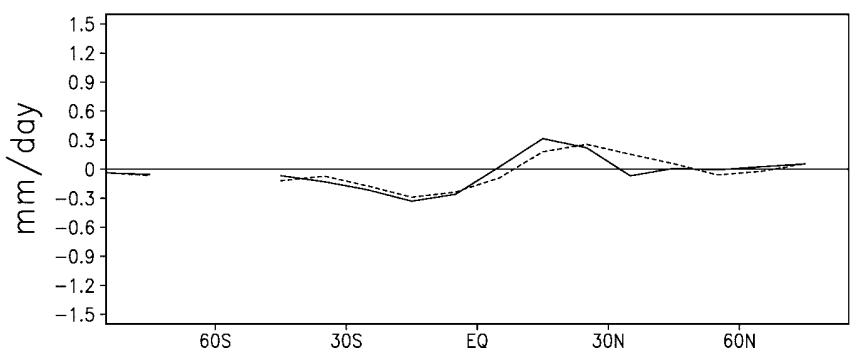

Fig. 4a-c Mean difference (Eemian minus control) in zonally averaged precipitation in JJA (top), DJF (middle) and the annual mean (bottom) as simulated by ECHAM-1/LSG (solid line) and CLIMBER-1 (dashed line) $\left(\mathrm{mm} \mathrm{day}^{-1}\right)$

changes in the meridional temperature gradient are smoother, and hence changes in the zonally averaged atmospheric circulation are not only restricted to the high latitudes.

\subsection{Mean ocean circulation}

The magnitude of the Atlantic meridional overturning circulation in the present control run is about $36 \mathrm{~Sv}$ in ECHAM-1/LSG (probably related to the high numerical diffusion in this model, Manabe and Stouffer 1999) and $17 \mathrm{~Sv}$ in CLIMBER-2 (Figs. 6a/7a). Similar differences are found in the Pacific (Figs. 6c/7c). The response of the meridional overturning circulation simulated by CLIMBER-2 and ECHAM-1/LSG in each ocean basin differs in several ways: in the Atlantic Ocean, while ECHAM-1/LSG shows a slight intensification (about $2 \mathrm{~Sv}$, less than $6 \%$, Fig. $6 \mathrm{~b}$, caused by a slight decrease of the net freshwater flux north of $40^{\circ} \mathrm{N}$ as shown in Montoya et al. 2000), CLIMBER-2 shows a weakening up to $3.5 \mathrm{~Sv}(-20 \%$, Fig. $7 b)$. This response can be explained by the enhanced warming of high northern latitudes and enhanced freshwater flux into the North Atlantic, resulting in a stabilization of the water column, a reduction in convection and a decrease of the oceanic meridional temperature gradient. These factors regulate the strength of the overturning (Rahmstorf 1996).

In the Pacific Ocean, CLIMBER-2 shows essentially no differences (Fig. 7d), while in ECHAM-1/LSG the meridional overturning circulation is intensified. In addition, there is an anomalous intermediate flow of up to $2 \mathrm{~Sv}$ triggered by convection at high northern latitudes leading to intermediate water formation, upwelling further south, and a northward return flow at the surface (Fig. 6d). This response is caused by changes in the freshwater flux balance over the northern Pacific in this model (Montoya et al. 2000).

The different simulated oceanic responses have different consequences on mid-high latitude temperatures. The changes in oceanic circulation simulated by ECHAM-1/LSG, mainly in the Pacific, contribute to an increase of the northward global heat transport by $10 \%$ (Fig. 8a-c), which contributes to the slightly enhanced midlatitude warming in DJF. In contrast to this, the weakened Atlantic overturning in CLIMBER-2 results in a reduction in northward heat transport up to $60^{\circ} \mathrm{N}$ by more than $10 \%$. This is not balanced by changes in the meridional heat transport in the other oceans and thus contributes together with decreased northward atmospheric heat transport to the mid-latitude cooling in DJF as observed in this model.

\section{Sensitivity experiments}

The fast turnaround time of CLIMBER-2 in comparison with GCMs permits us to perform a number of sensitivity experiments to attempt to explain the possible reasons for the differences between the two model responses. Firstly, since the fundamental difference between the model responses is that of the thermohaline circulation, which is ultimately driven by temperature and salinity, CLIMBER-2 was forced with the freshwater flux anomalies obtained with ECHAM-1/LSG (Sect. 4.1). Secondly, the effects of altered insolation and $\mathrm{CO}_{2}$ were analyzed separately (Sect. 4.2). Finally, CLIMBER-2 was used to study the effects of changes in vegetation (Sect. 4.3). The effects of the different climate subsystems are described in terms of amplification factors (Sect. 4.4).

\subsection{Freshwater flux run}

The main difference between the responses of the two models is that of the thermohaline circulation, which is ultimately driven by buoyancy (heat and freshwater fluxes). Since the temperature response from both models at high northern latitudes reflects a warming 
a

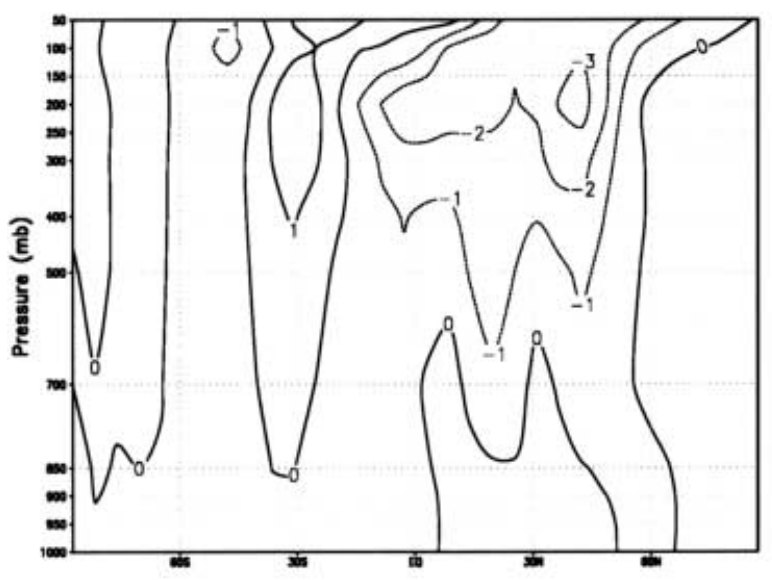

b

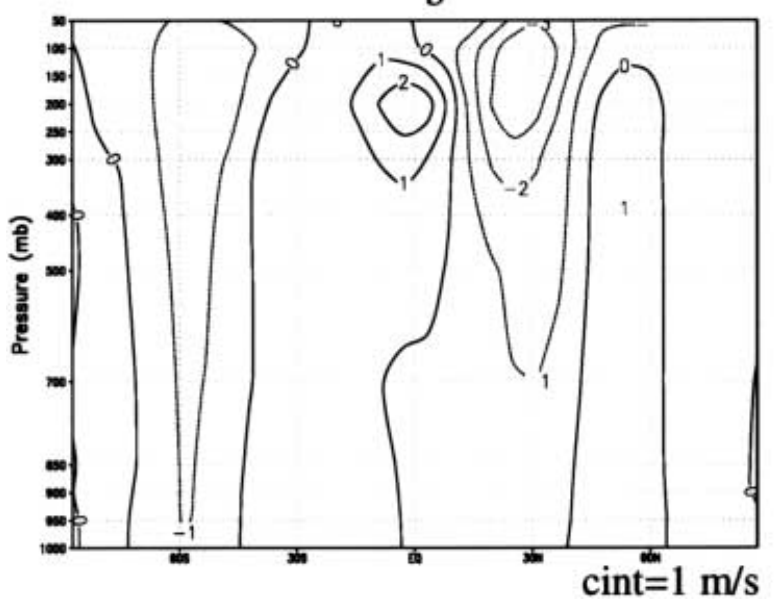

C

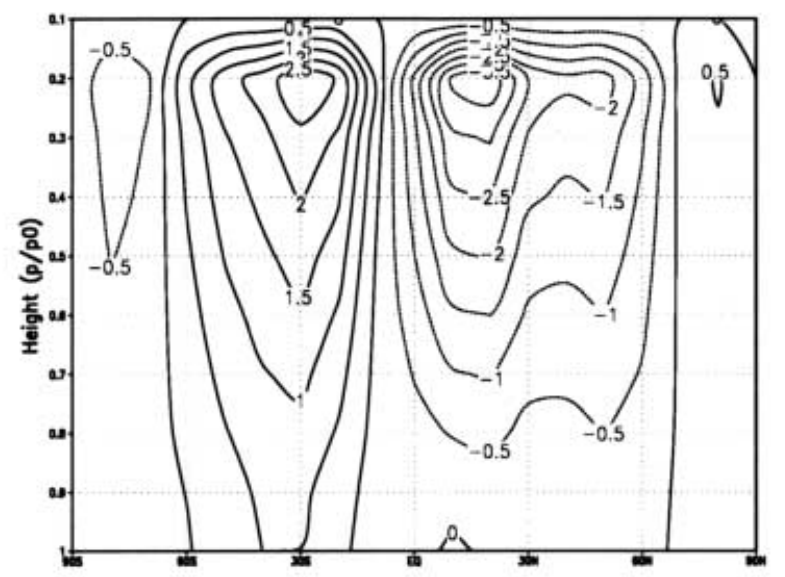

d

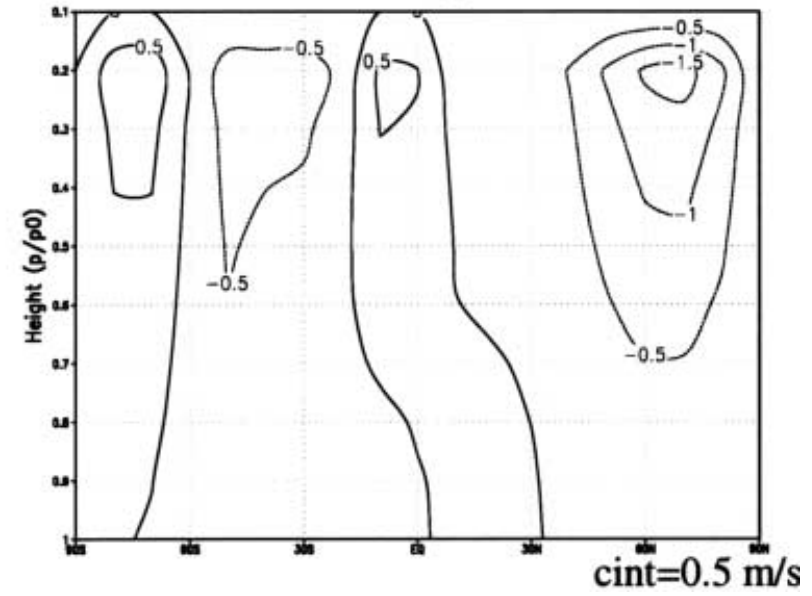

Fig. 5a-d Mean difference (Eemian minus control) in zonally averaged zonal velocity for a JJA and b DJF, as simulated by ECHAM-1/LSG and $\mathbf{c}$ JJA and d DJF, as simulated by CLIMBER-2 $\left(\mathrm{m} \mathrm{s}^{-1}\right)$

rather than a cooling throughout the year (Fig. 2a-d), we tested whether the differences in the thermohaline circulation can be attributed to differences in the simulated freshwater fluxes. To this end, CLIMBER-2 was forced for the Eemian with the global field of the freshwater flux anomalies obtained by ECHAM-1/LSG. Thus the ocean characteristics were calculated interactively (just like in the previous Eemian simulation) but the freshwater fluxes were fixed as the sum of the mean flux from the CLIMBER-2 control simulation plus the mean flux difference (Eemian minus control) between the two ECHAM-1/LSG simulations (hence, the forcing freshwater flux was constant in time except for the seasonal cycle).

In CLIMBER-2 the decreased freshwater flux into the North Pacific as imposed from the ECHAM-1/LSG differences results in a similar anomalous circulation pattern (Fig. 9) to that found in ECHAM-1/LSG (see Sect. 3.5). The Pacific meridional overturning circulation is intensified in comparison with the control run with an anomalous intermediate flow of about $3 \mathrm{~Sv}$. The North Atlantic overturning cell (not shown) is enhanced (rel- ative to the previous Eemian run), as surface salinity is increased due to the imposed ECHAM-1/LSG freshwater flux differences, which demonstrates the potential of the freshwater forcing. However, the overturning circulation is still weaker than for the control run (see Sect. 3.5) in contrast to the response simulated by ECHAM-1/LSG. We attribute this to the fact that the warming at high northern latitudes simulated by ECHAM-1/LSG has a much smaller amplitude than that simulated by CLIMBER-2. Studies with a modified CLIMBER version indicate that in high northern latitudes the albedo effect might have been overestimated, but discrepancies might as well reflect deficiencies in the sea-ice performance of ECHAM-1/LSG. Hence, in CLIMBER-2 the warming overcompensates the decreased freshwater flux and the response of the overturning circulation remains a reduction instead of an intensification.

Thus, the main differences in the ocean meridional heat transport (not shown) due to the fixing of the freshwater fluxes from the atmosphere can be observed in the Pacific where the increased northward heat 
a
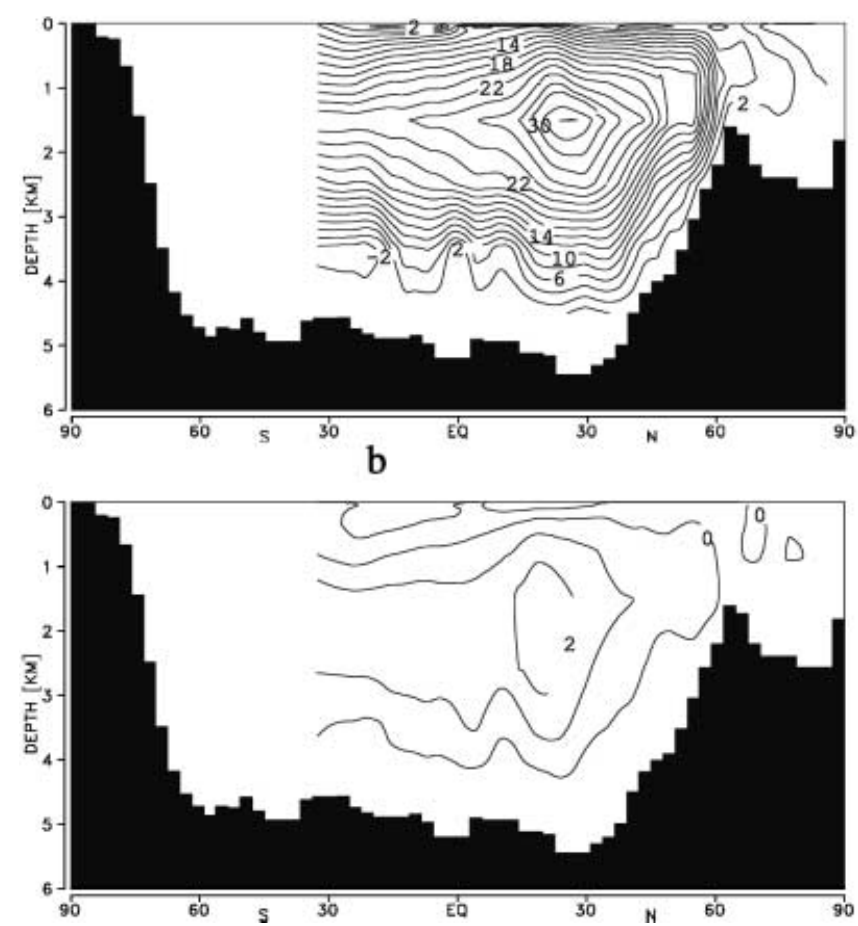

Fig. 6a-d Zonally averaged mass transport stream function of the meridional overturning circulation as simulated by ECHAM-1/LSG in the Atlantic Ocean a for the control run, $\mathbf{b}$ for the difference Eemian

a
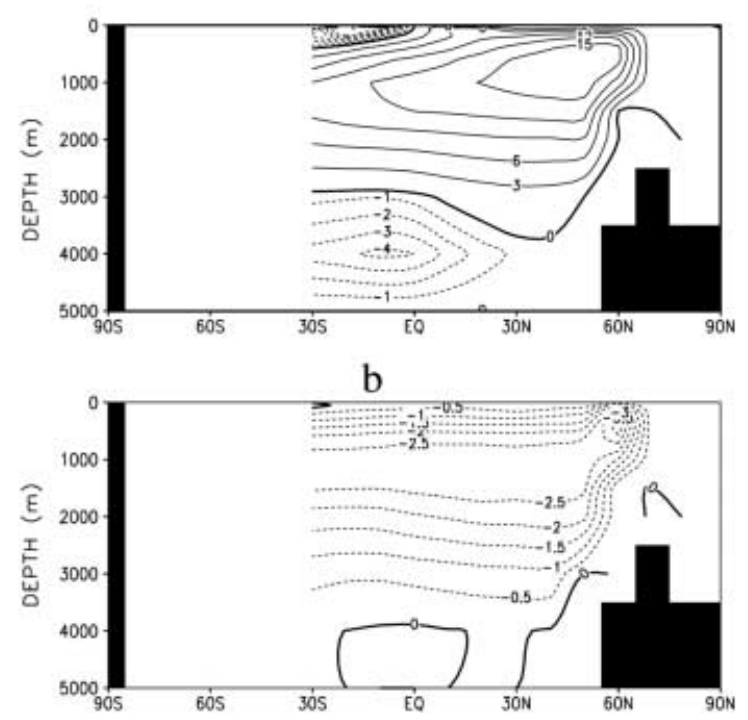

Fig. 7a-d Zonally averaged mass transport stream function of the meridional overturning circulation as simulated by CLIMBER-2 in the Atlantic Ocean a for the control run, $\mathbf{b}$ for the difference Eemian

transport might contribute to the slight warming of some parts of the middle and higher northern latitudes. This brings the temperature response of CLIMBER in these regions slightly closer to that of ECHAM-1/LSG (see Sect. 3.1). c
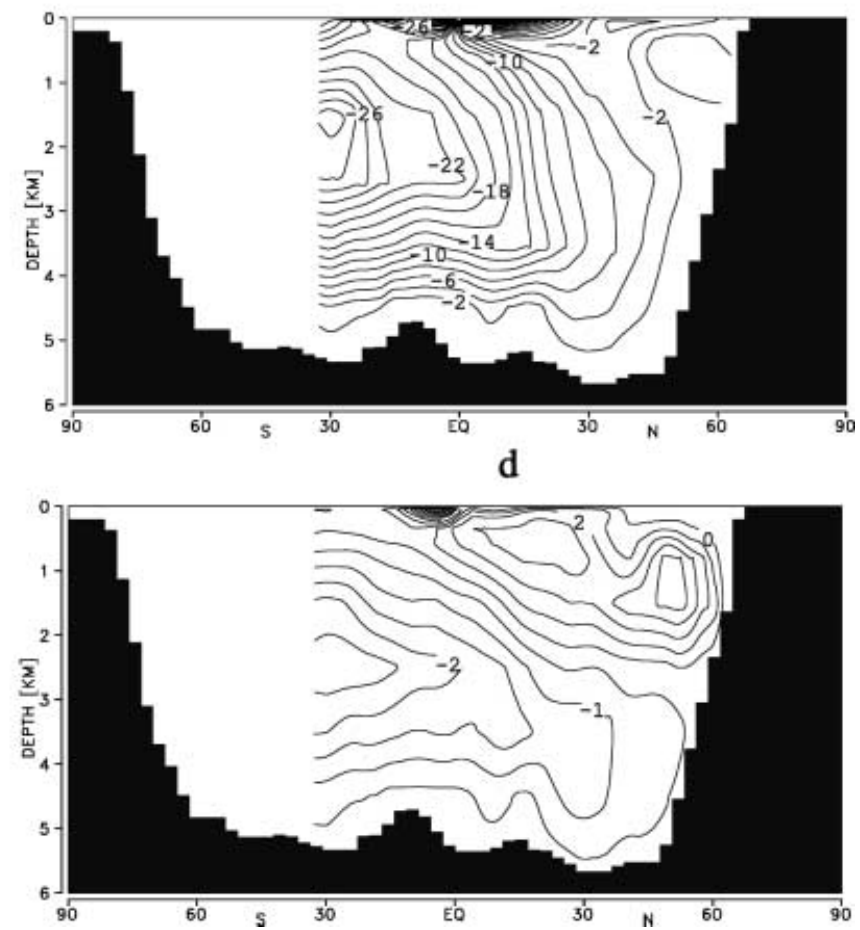

minus control run, and in the Pacific Ocean $\mathbf{c}$ for the control run, $\mathbf{d}$ for the difference Eemian minus control run (Sv)
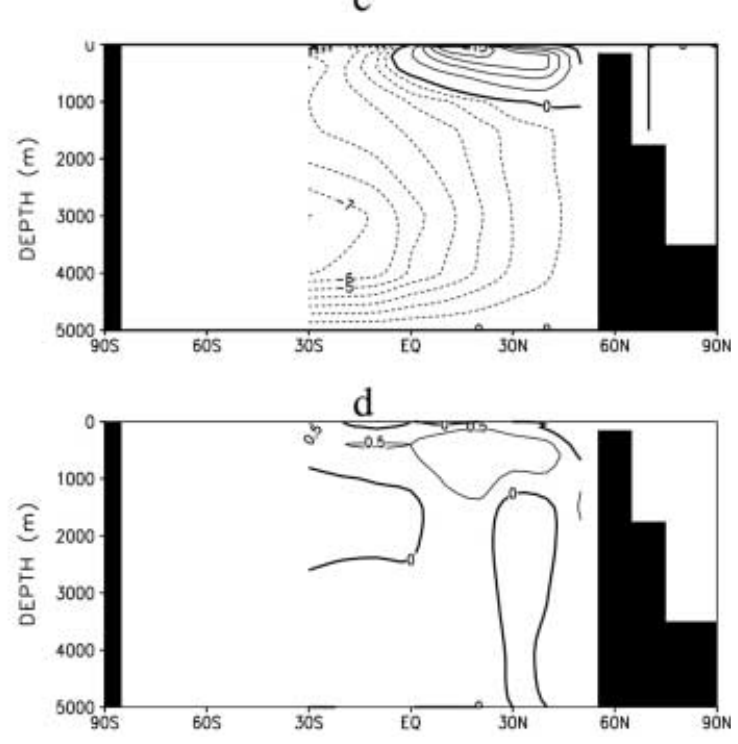

minus control run, and in the Pacific Ocean $\mathbf{c}$ for the control run, $\mathbf{d}$ for the difference Eemian minus control run (Sv)

\subsection{Radiative forcing}

The external forcing of the Eemian and control runs in the previous simulations differed in two ways: (1) atmospheric $\mathrm{CO}_{2}$ concentration, and (2) insolation. To 
isolate the effect of insolation on the climate response, an additional run with preindustrial $\mathrm{CO}_{2}(280 \mathrm{ppmv}$, as in the Eemian run) and modern insolation was per-
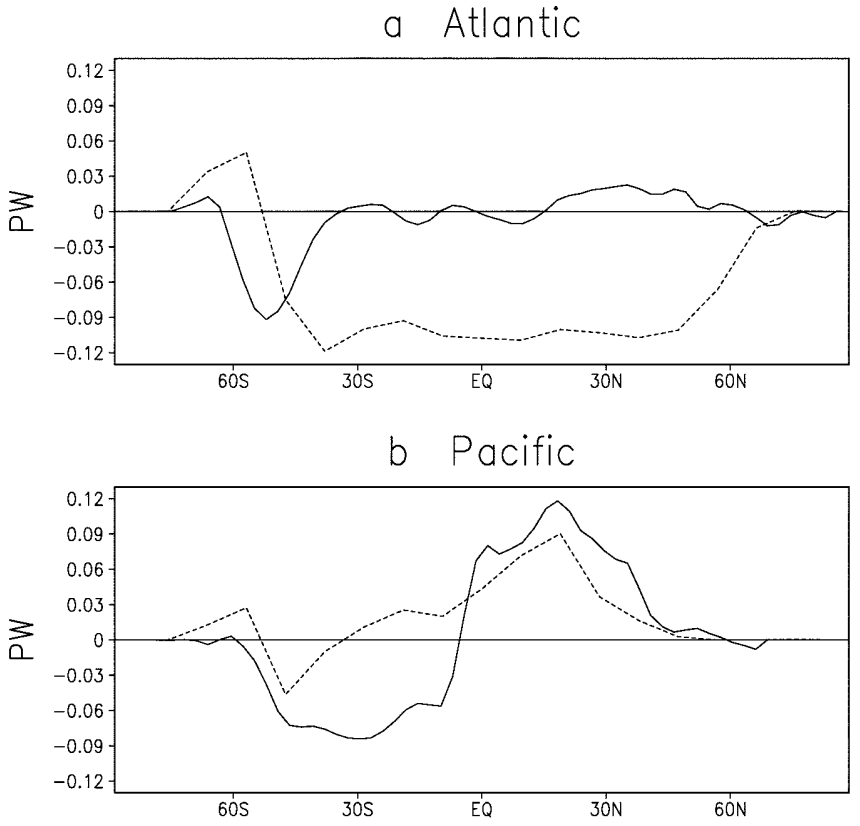

c Indian

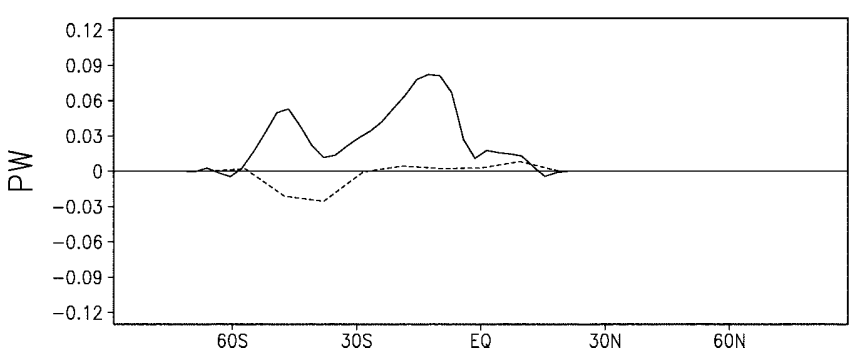

Fig. 8a-c Mean difference (Eemian minus control) in northward heat transport in the Atlantic (top), Pacific (middle) and Indian Ocean (bottom) as simulated by ECHAM-1/LSG (solid line) and CLIMBER2 (dashed line)

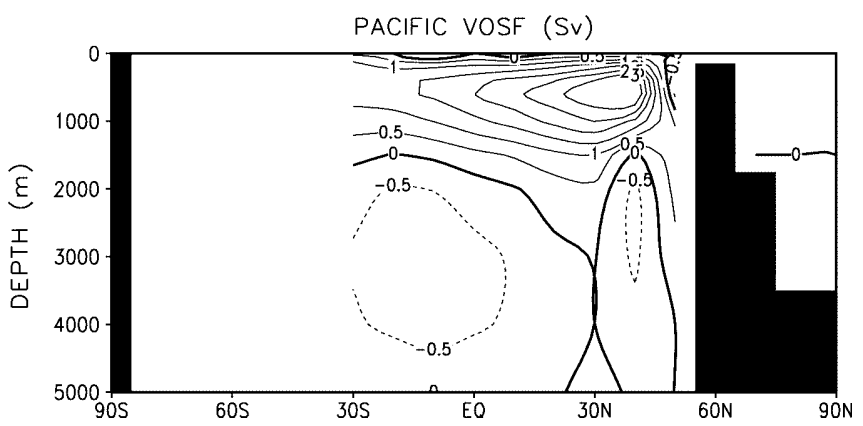

Fig. 9 Response as simulated by CLIMBER-2 (deviation with respect to the control run) of the zonally averaged mass transport stream function of the meridional overturning circulation in the Pacific Ocean for the experiment in which the freshwater flux into the ocean is fixed as that of the control run as simulated by CLIMBER-2 plus the anomalies (Eemian minus control run) as simulated by ECHAM-1/ LSG (Sv) formed with CLIMBER-2. This is more than an academic exercise, since the present-day climate is not in equilibrium with the currently increasing $\mathrm{CO}_{2}$ levels and paleodata reflect mean values over at least several hundred years. Thus, for comparison with the paleodata, it is more reasonable to use preindustrial conditions, for which the assumption of such an equilibrium is more reasonable, as control simulation (hereafter preindustrial control run) than the former control run ("present" control run) with present $\mathrm{CO}_{2}$ levels.

Temperature differences relative to the preindustrial control run reach values of $+6{ }^{\circ} \mathrm{C}$ in summer over the Northern Hemisphere continents, whereas winter time cooling does not exceed $-2{ }^{\circ} \mathrm{C}$ (Fig. 10a, b, in comparison with Fig. 2c, d), which shows some similarities with Harrison et al. (1995). In the Southern Hemisphere, austral winter and spring temperatures now are higher for the Eemian than for the preindustrial climate. The annual mean temperature differences show a warming for the Eemian over nearly the whole globe (not shown), with a globally averaged change of $0.4{ }^{\circ} \mathrm{C}$. Annual precipitation is higher in most areas, especially in the regions of increased summer monsoons in north Africa, south west Asia, and east Asia (not shown). The global annual change is $0.05 \mathrm{~mm} /$ day. The Atlantic meridional
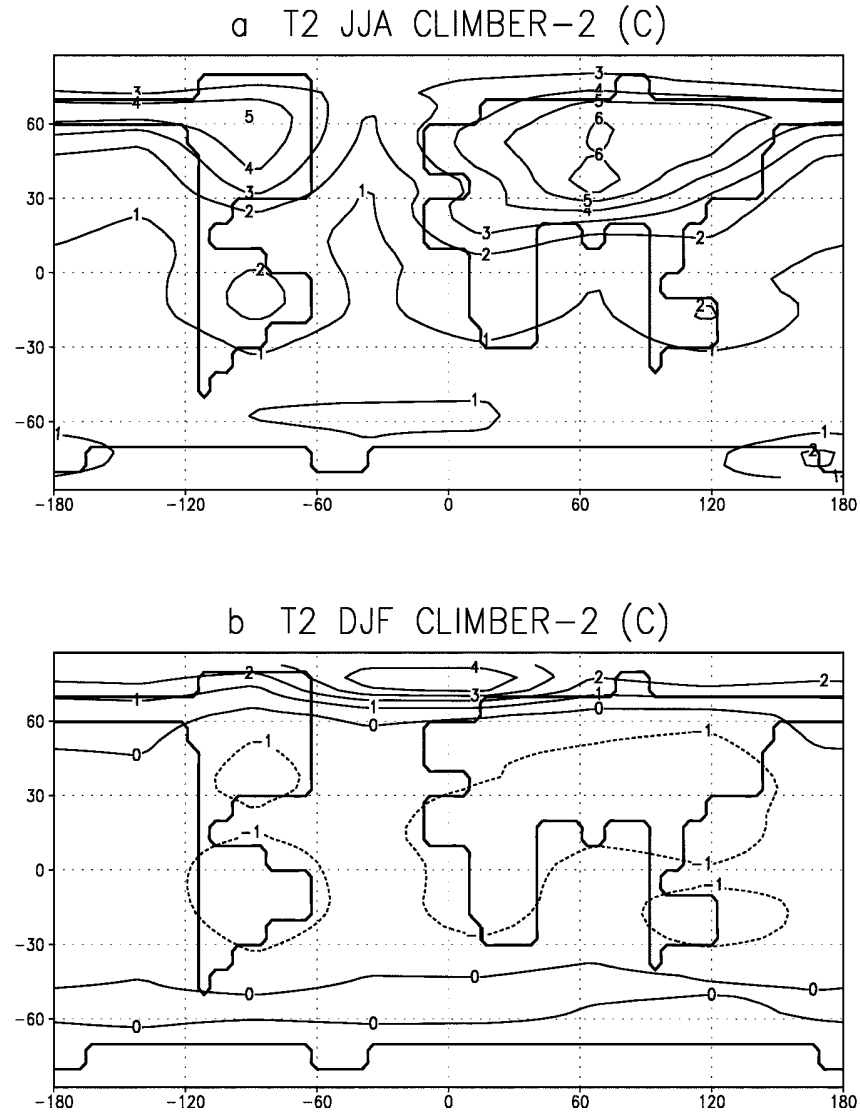

Fig. 10a, b Mean difference in near surface temperature between the Eemian run and the control run with preindustrial $\mathrm{CO}_{2}$ concentration for a JJA and b DJF, as simulated by CLIMBER-2 $\left({ }^{\circ} \mathrm{C}\right)$ 

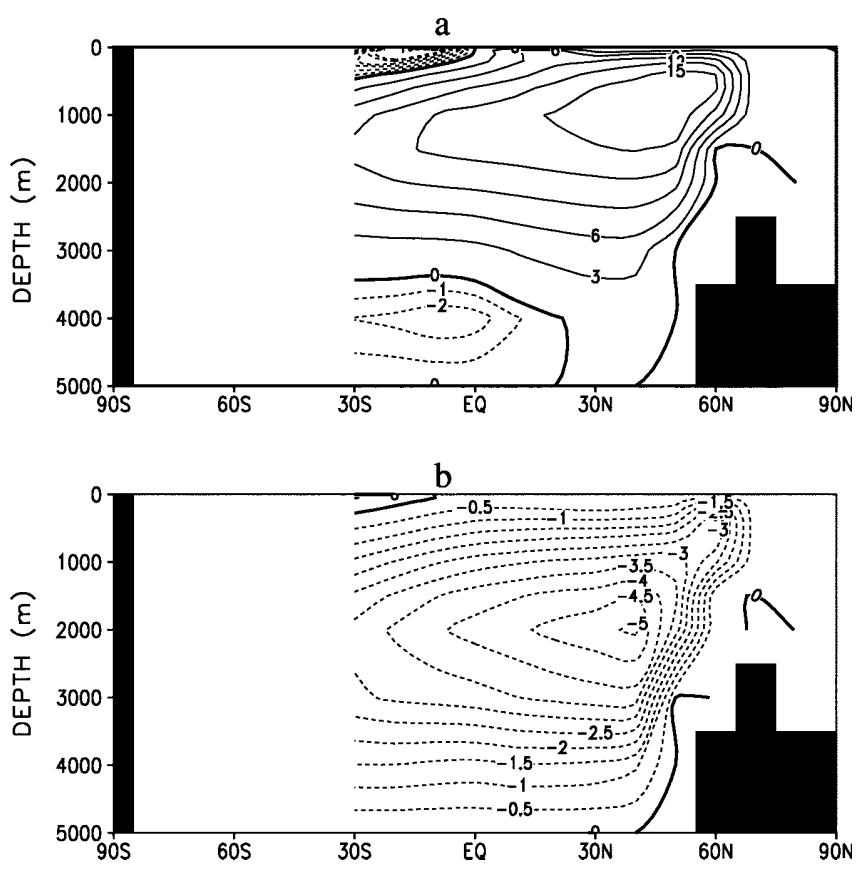

Fig. 11a, b Zonally averaged mass transport stream function of the meridional overturning circulation in the Atlantic Ocean a for the control run, $\mathbf{b}$ for the difference between the Eemian run and the control run as simulated by CLIMBER-2 (Sv). All simulations run with preindustrial $\mathrm{CO}_{2}$ concentration

overturning circulation is further weakened, while AABW (Antarctic Bottom Water) is stronger and penetrates farther north (Fig. 11). The northward meridional heat flux in the North Atlantic is reduced by about $0.1 \mathrm{PW}$; about $0.05 \mathrm{~Sv}$ less freshwater is transported into the Atlantic basin (not shown).

\subsection{Vegetation feedbacks}

Up to now, vegetation characteristics were fixed to their modern state, which is an unrealistic assumption since vegetation will also change under altered climatic conditions, with the potential to affect the climate response further. To investigate the role of vegetation in the climate response at the Eemian, additional simulations for the Eemian have been performed with CLIMBER-2:

1. A simulation $A O V$ in which not only the ocean but also the vegetation was allowed to react to the changed orbital forcing. Changes between results of simulations $A O V$ and $A O$ include not only the pure impact of vegetation changes on climate but also the impact of interactions between feedbacks operating in different climate sub-systems, i.e., synergistic effects;

2. Two additional experiments, simulations $A V$ and $A$ (Sect. 2.2), whose comparison allows us to estimate the sole effect of interactive vegetation. Results of the latter experiment (Figs. 12/13) compare satisfactorily with atmospheric GCM results of de Noblet et al. (1996).

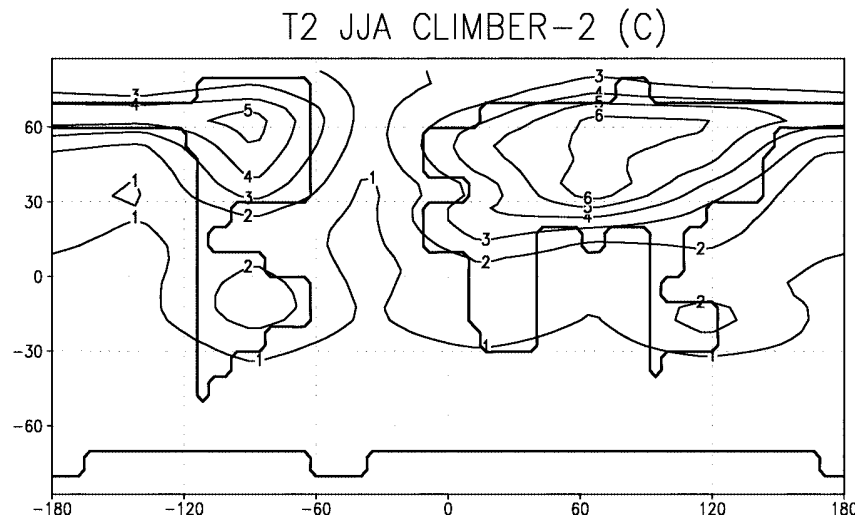

Fig. 12 Mean difference in near surface temperature for JJA between the Eemian and the control run, obtained by integrating the atmosphere-only and the atmosphere-ocean coupled versions of CLIMBER-2, respectively $\left({ }^{\circ} \mathrm{C}\right)$. All simulations run with preindustrial $\mathrm{CO}_{2}$ concentration

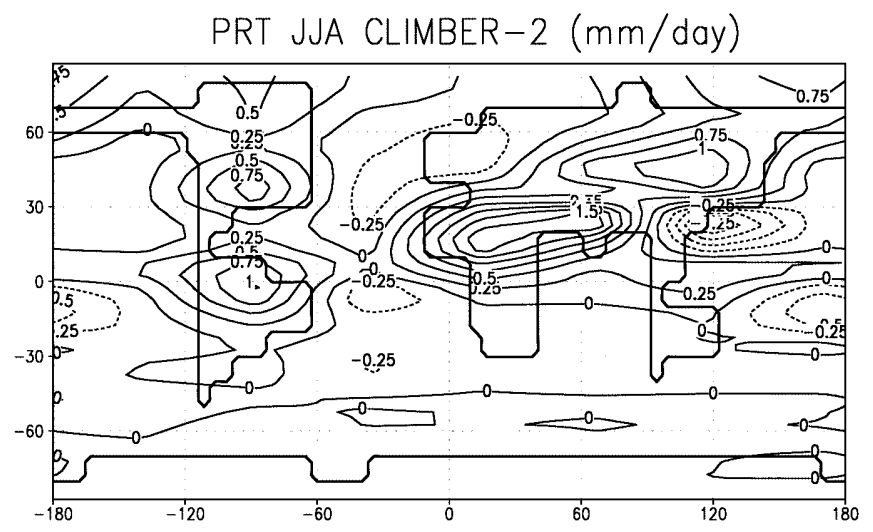

Fig. 13 Mean difference in total precipitation for JJA between the Eemian and the control run, obtained by integrating the atmosphereonly and the atmosphere-ocean coupled versions of CLIMBER-2, respectively $\left(\mathrm{mm} \mathrm{day}^{-1}\right)$. All simulations run with preindustrial $\mathrm{CO}_{2}$ concentration

The main differences in the thermal response due to interactive vegetation solely are found at high northern latitudes. Because of warmer summers and longer growing seasons at the Eemian, the forests in $A V$ expand farther northward relative to $A$. The rougher surface in $A V$ lead to a lower albedo, which together with the earlier snow melting results in additional warming (Table 2). In equilibrium, the area of tundra (grass) and (polar) desert to the north of $60^{\circ} \mathrm{N}$ is decreased by some $4.6 \times 10^{6} \mathrm{~km}^{2}$ (see also Fig. 14a). In $A O V$ these patterns are even more pronounced. There the warmer conditions additionally lead to a significant decrease of the sea-ice area which, due to the lower albedo of open water, results in an additional warming. Thus, in $A O V$ both the vegetation-snow-albedo feedback and the sea-ice albedo-SST feedback lead to a strong amplification of the individual warming signals and to a final decrease of the area of tundra and polar desert by some $5.3 \times 10^{6} \mathrm{~km}^{2}$ (see also Fig. 14a). 

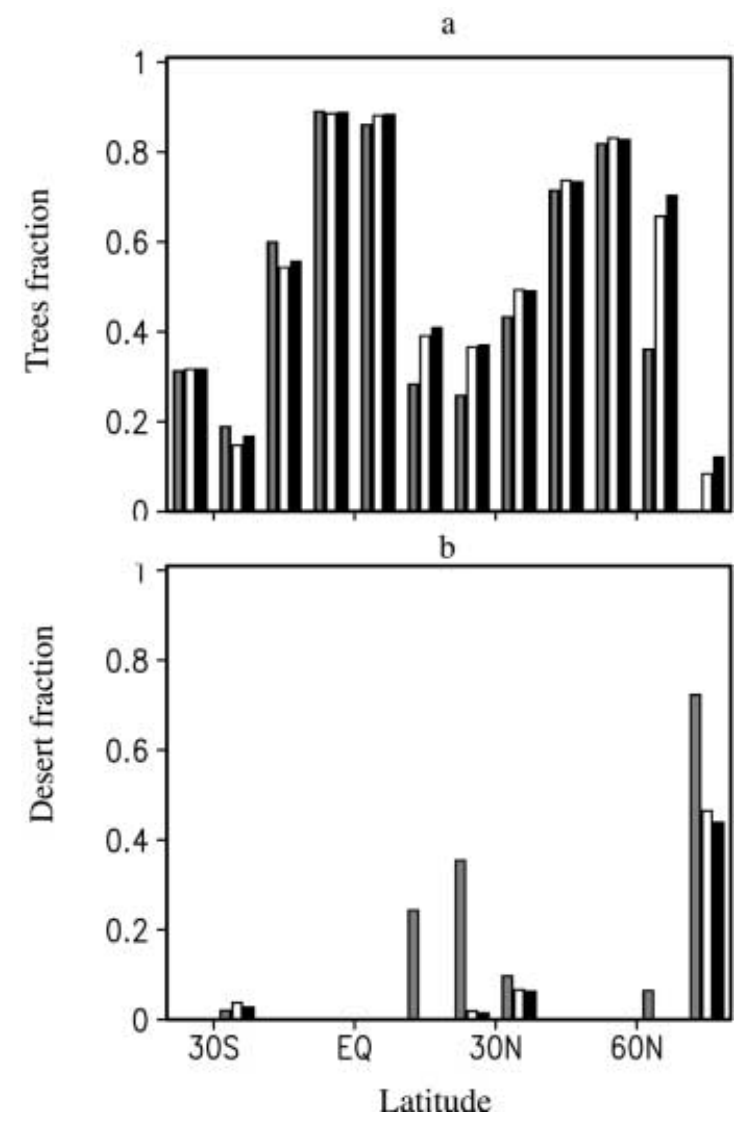

Fig. 14a, b Zonally averaged trees (upper panel) and desert (lower panel) fraction for the CLIMBER-2 control run (gray), and the Eemian climate simulations with the atmosphere-vegetation model $A V$ (white) and with the atmosphere-ocean-vegetation model $A O V$ (black) (fraction). All simulations run with preindustrial $\mathrm{CO}_{2}$ concentration

The main differences in the precipitation response between $A V$ and $A$ are found in the subtropics, especially in North Africa (Table 2), where the increase of summer monsoon precipitation at the Eemian leads to an expansion of vegetation in $A V$. Subsequent changes in the radiation balance lead to a surplus in available energy which is used for evaporation. The increase of atmospheric total energy (sensible plus latent heat) results in enhanced convection (Charney et al. 1976) and together with changes in the moisture advection in additional precipitation increase (Claussen 1997). In equilibrium, $97 \%$ of north Africa is covered by vegetation (see also Fig. 14b), 81\% of which are grass. Patterns in $A O V$ are quite similar suggesting the interactive ocean being less important here than in higher latitudes.

In $A O V$ a further weakening of the Atlantic meridional overturning circulation of $7 \mathrm{~Sv}$ with respect to the preindustrial control run is found. As result, less heat is transported into the North Atlantic translating in warmer Southern Oceans. The possibility of a warming effect of the reduced overturning circulation in the South Atlantic during the last interglacial has already been discussed by Crowley and Kim (1992).

\subsection{Amplification factors}

To underline the importance of interactive vegetation and to estimate the contribution of the different climate sub-systems and their interaction in obtaining the results of the coupled atmosphere-ocean-vegetation system, amplification factors are calculated for various climate variables and for different regions and seasons. This analysis is suggested as a clear method for showing to which extent each of the climate sub-systems and synergisms amplifies or diminishes the response of the atmosphere-only model when going over from modern to Eemian conditions.

For the four CLIMBER-2 simulations $A, A O, A V$, and $A O V, \triangle$ is used to express the difference of a variable between a certain simulation and the preindustrial control run. Then the response of a variable in the coupled atmosphere-ocean-vegetation system can be written as the sum of the response of the atmosphereonly system plus the pure effects of the ocean $\Delta O$, the vegetation $\Delta V$, and the synergism due to changes in the ocean and in the vegetation characteristics $\triangle S Y N$ :

$$
\begin{aligned}
\Delta A O V & =\Delta A+(\Delta A O-\Delta A)+(\Delta A V-\Delta A)+\Delta S Y N \\
& =\Delta A+\Delta O+\Delta V+\Delta S Y N .
\end{aligned}
$$

$\triangle S Y N$ (as well as $\Delta O$ and $\Delta V$ ) cannot directly be simulated. Instead all the four other experiments (plus the control run) are needed to calculate $\triangle S Y N$ from the differences obtained there according to

$\Delta S Y N=\triangle A O V-(\triangle A O+\triangle A V)+\Delta A$.

This approach is comparable to that described in Dutrieux and Berger (1996) and Berger (2000) and can be traced back to the factor separation technique of Stein and Alpert (1993) which can be interpreted in terms of a Taylor expansion. It can be directly seen that for example the pure effect of interactive vegetation cannot be derived by comparing the fully coupled simulation with the simulation with fixed vegetation as this would give

$\triangle A O V-\triangle A O=\Delta V+\triangle S Y N$,

which, on the right hand side, gives not only the pure contribution of the vegetation but includes also the synergistic effect as already discussed in Sect. 4.3.

To give a feeling of to which extent the different contributors amplify or diminish the initial response of the atmosphere-only model one can multiply and divide the whole Eq. (1) by $\Delta A$ leading to

$f_{A O V} * \Delta A=\Delta A+f_{O} * \Delta A+f_{V} * \Delta A+f_{S Y N} * \Delta A$

with the (additive) amplification factors $f_{i}$.

These amplification factors were calculated for different climate variables, times, and regions (see Table 3 ). In the Northern Hemisphere, the pure responses of the vegetation and of the ocean are, in the annual mean, at the most as high as the response of the atmosphere. On the other hand, nearly half of the signal of the fully coupled model is due to synergistic effects. The picture is different for JJA means. Here, the pure response of the 
Table 3 Pure contributions of ocean $(\Delta O)$, vegetation $(\Delta V)$, and of synergism due to changing ocean and vegetation conditions $(\triangle S Y N)$ and factors $f_{i}$ describing the amplification of the pure atmospheric response due to the different components $O, V$, and $S Y N$ as well as due to the coupling of atmosphere, ocean, and vegetation $A O V$ (see Sect. 4.4). Values are for the same characteristics, regions and times as in Table 2 (for CLIMBER-2 results for Eemian minus preindustrial climate, both with a $\mathrm{CO}_{2}$ concentration of $280 \mathrm{ppmv}$ )

\begin{tabular}{|c|c|c|c|c|c|c|}
\hline & \multicolumn{3}{|l|}{$\mathrm{T}\left({ }^{\circ} \mathrm{C}\right)$} & \multicolumn{3}{|c|}{ Precipitation $\left(\mathrm{mm} \mathrm{day}{ }^{-1}\right)$} \\
\hline $\begin{array}{l}\Delta O \\
\Delta V \\
\Delta S Y N\end{array}$ & $\begin{array}{l}0.2(-0.2) \\
0.4(0.7) \\
0.7(0.7)\end{array}$ & $\begin{array}{l}0.3(-0.0) \\
0.2(0.4) \\
0.7(0.6)\end{array}$ & $\begin{array}{l}0.2(0.1) \\
0.0(0.1) \\
0.5(0.6)\end{array}$ & $\begin{array}{c}-0.00(-0.02) \\
0.14(0.31) \\
0.09(0.13)\end{array}$ & $\begin{array}{r}0.04(-0.01) \\
-0.00(0.01) \\
0.07(0.04)\end{array}$ & $\begin{array}{l}0.00(-0.04) \\
0.63(1.55) \\
0.13(0.29)\end{array}$ \\
\hline $\begin{array}{l}f_{O} \\
f_{V} \\
f_{A O V} \\
f_{S Y N}\end{array}$ & $\begin{array}{l}0.5(-0.1) \\
0.9(0.2) \\
4.0(1.3) \\
1.6(0.2)\end{array}$ & $\begin{array}{l}1.0(-0.0) \\
0.8(0.2) \\
5.4(1.4) \\
2.6(0.2)\end{array}$ & $\begin{array}{r}2.9(0.1) \\
0.6(0.1) \\
12.5(1.8) \\
8.0(0.7)\end{array}$ & $\begin{array}{c}-0.02(-0.04) \\
0.73(0.49) \\
2.18(1.66) \\
0.46(0.21)\end{array}$ & $\begin{array}{r}-0.62(-0.05) \\
0.02(0.04) \\
-0.60(1.21) \\
-1.00(0.23)\end{array}$ & $\begin{array}{l}0.01(-0.02) \\
1.36(0.97) \\
2.64(2.13) \\
0.27(0.18)\end{array}$ \\
\hline
\end{tabular}

atmosphere is of major importance. Vegetation, ocean, and synergisms play only a minor role in the summer means, they are much more important in the other seasons (not shown here), when vegetation-snow-albedo feedback and sea-ice albedo-SST feedbacks work. For Northern Hemisphere temperatures, synergistic effects are always of the same sign as vegetation impact whereas there is a time lag in the response of the ocean due to its thermal inertia. For precipitation in North Africa however, the impact of vegetation is dominant and accounts for about half of the signal of the fully coupled model, both in annual and in JJA means. The ocean has nearly no impact on precipitation and thus vegetation changes in the Sahara and also the synergistic effects are of secondary importance here. The same is valid for the other seasons (not shown here).

\section{Conclusions and discussion}

Two coupled ocean-atmosphere climate models have been employed to simulate climatic conditions at the last interglacial maximum or Eemian (about 125000 years before present): the atmosphere-ocean GCM ECHAM$1 / \mathrm{LSG}$ and the climate system model of intermediate complexity CLIMBER-2. Comparison of the results reveals a broad agreement in most large-scale features (warming over northern landmasses in summer and cooling in winter, intensified northern summer monsoons, an all-year-round warming at high northern latitudes, and reduced midlatitude westerly flow throughout the troposphere), but certain disagreements are also found. Essentially, the models differ in two points:

1. In the Southern Hemisphere the underestimated sea-ice thickness and extent in the control run in ECHAM-1/LSG leads to a reduced sea-ice-albedofeedback and a smaller increase of sea-ice at high southern latitudes and therefore higher mean annual temperatures than in CLIMBER-2;

2. The response of the ocean circulation to the altered boundary conditions: in CLIMBER-2 the meridional overturning circulation is attenuated in the Atlantic and is not altered in the Pacific while in ECHAM-1 LSG it is intensified both in the Atlantic and Pacific.

Disagreement in the Atlantic Ocean appears to be caused by the different magnitudes of the high northern latitude warming simulated by the two models, since even when identical freshwater forcing is imposed the model responses remain opposite. In the Pacific Ocean the discrepancy can be attributed to different freshwater flux anomalies simulated by the models, which translates into differences in the northward heat transport and hence contributes to discrepancies concerning the thermal response of the climate system and the atmospheric circulation at mid-high northern latitudes. The freshwater fluxes are ultimately dependent on the parametrization of evaporation, precipitation and the runoff scheme employed. This study demonstrates the importance of the accurate simulation of such processes due to their potential for affecting the global climatic response.

The previous results refer to deviations with respect to a control run with present $\mathrm{CO}_{2}$ levels. However, due to the rapid increase of the atmospheric $\mathrm{CO}_{2}$ concentration in the past hundred years, the present climate is not in equilibrium with such high levels, and paleodata rather reflect deviations with respect to the last several hundred years. For this reason it is more appropriate to study the deviations with respect to a control run with a preindustrial $\mathrm{CO}_{2}$ concentration, as with CLIMBER-2. Some of the difference patterns between Eemian and preindustrial climate simulated by CLIMBER-2 seem to be in better agreement with most of the available evidence of the geological record than those relative to the "present-day" (i.e., 346 ppmv $\mathrm{CO}_{2}$ ) control run:

1. Whereas comparison with the "present-day" control run resulted in a mean annual cooling at mid-northern latitudes for the Eemian in CLIMBER-2, results relative to the preindustrial control run reveal a warming, as suggested by geological data (van der Hammen 1971; Miller et al. 1983; Pons et al. 1992). On the other hand, such a warming was also found in the ECHAM-1/LSG model, in part as a result of the aforementioned changes in the ocean circulation. 
Many of the paleodata indicate summer and/or winter warming at the Eemian (Aalbersberg and Litt 1998; Cortijo et al. 1994; Ruddiman and McIntyre 1976; Woillard 1978; LIGA 1991; Zagwijn 1996). Others are ambiguous as to whether conditions were warmer, or cooler than present both over land and over ocean (Cortijo et al. 1994; CLIMAP 1984; Ruddiman 1985; LIGA 1991; Crowley 1981). Northern Hemispheric maps by Borzenkova et al. (1992), Frenzel (1992) and Velichko et al. (1992) for summer and winter agree in showing a strong temperature gradient decrease, with maximum temperatures increases above $+6{ }^{\circ} \mathrm{C}$ over the northernmost parts of Asia.

2. Mean annual precipitation deviations relative to the preindustrial control run over the Southern Hemisphere, and the northern tropics are enhanced in comparison to deviations relative to the "presentday" control run. This result is in better agreement with the assumption that enhanced summer monsoon precipitation at time periods of maximum precession translates into enhanced total precipitation over land in the annual mean, and with geological evidence suggesting enhanced carbon storage on land at time periods of maximum precession, as would be the case for the Eemian (Keigwin and Boyle 1985). The simulated drier conditions in Europe might be reasonable for the southern (Pons et al. 1992) but not for the northern part (LIGA 1991).

3. Results relative to the preindustrial control run reveal a further weakening of Atlantic meridional overturning circulation, in addition to that already found in results relative to the "present-day" control run, plus an intensification of AABW. This is in accordance with some of the evidence from changes in deep water circulation from $\delta^{13} \mathrm{C}$ data (Duplessy et al. 1984; Duplessy and Shackleton 1985), which are consistent with reduced North Atlantic Deep Water (NADW) formation but also with enhanced AABW. These in turn could be coupled responses, consistent with the greater surface stability due to the northern high-latitude warming. However, more recent $\delta^{13} \mathrm{C}$ and $\mathrm{Cd} / \mathrm{Ca}$ data from high-resolution sediment cores suggest NADW levels may have been the same as in the present (Adkins et al. 1998; Oppo et al. 1997).

4. Comparison with the preindustrial control run reveals that the pronounced cooling found in the Southern Hemisphere with CLIMBER-2 relative to the "present" control run can be attributed to the differences in the $\mathrm{CO}_{2}$ levels. Nevertheless, the warming as shown in Borzenkova et al. (1992) and Hays et al. (1976) is still underestimated. Vostok ice-core data (Jouzel et al. 1987) give annual temperatures similar to the present for $125 \mathrm{kyBP}$ but warming of up to $2{ }^{\circ} \mathrm{C}$ for the previous 5000 years. Whether this time shift reflects an uncertainty in the dating, and hence depends on the time scale applied (Jouzel et al. 1993), or is a real offset (Crowley 1990) is still an open question.
In the previous runs, vegetation was fixed to its modern state. As vegetation changes with changing climatic conditions, this is not a realistic assumption. Thus in a final change interactive vegetation was included in CLIMBER-2. Again, agreement with some of the paleodata could be improved:

1. In high northern latitudes warming due to the sea icealbedo feedback, which is already found in the previous runs with fixed vegetation, is now strongly amplified through the vegetation-snow-albedo feedback. As a result of this synergistic effect, the sea-ice area further decreases and the area of boreal forests increases by some $5.3 \times 10^{6} \mathrm{~km}^{2}$. This is in line with the findings of Grichuk (1992) for the last interglacial maximum, showing the Northern Hemisphere up to about $70^{\circ} \mathrm{N}$ mainly covered by different forest formations of boreal type, partly including patches of tundra, and an absence of polar deserts as well as a more limited distribution of tundra.

2 . In the subtropics extended vegetation strongly amplifies the monsoonal response to the insolation forcing. The model shows large parts of the modern Sahara covered by vegetation in the line of reconstructions by Le Houérou (1997), showing mediterranean forest and tropical savanna, and by Grichuk (1992) showing a mixture of savanna and open tropical forests, grass and bush formations of desert type, and bush-arboreal formations.

3. The Atlantic meridional overturning circulation is further reduced. As a consequence, temperatures further increase at high southern latitudes. This mechanism would hence provide synchronous warming in the Southern and Northern Hemispheres.

In all, the response of the atmosphere-ocean-vegetation system to the changes in insolation results in summer temperature differences over the Northern Hemisphere continents which rise to values of up to $7{ }^{\circ} \mathrm{C}$, while in winter the differences do not exceed $-1.5^{\circ} \mathrm{C}$. Together with further warming of the Southern Hemisphere, the change in globally averaged annual temperature in this case is $1.1{ }^{\circ} \mathrm{C}$. Vegetation feedbacks could hence cause globally warmer conditions which could not be accounted for in the simulations without interactive vegetation.

In conclusion the generally good agreement of the climate response by two models of two different classes (the ECHAM-1/LSG GCM and the CLIMBER-2 climate model of intermediate complexity) to the same forcing supports the consideration of CLIMBER-2 as an appropriate tool for the study of large-scale, long-term climate characteristics. An advantage is its fast turnaround time which permits carrying out a large number of simulations. In this work, the sensitivity studies help to analyze reasons for the differences between the results of the two models as well as for deviations from the paleodata. Investigating the role of atmospheric $\mathrm{CO}_{2}$ concentration as well as of interactive vegetation (missing in the ECHAM-1/LSG simulations) underlines the importance of careful experimental design. Choosing the more reasonable preindus- 
Fig. 15a, b Zonally averaged temperature differences for a JJA and b DJF for four different Eemian runs: ECHAM-1/ LSG (solid) and CLIMBER-2 in its atmosphere-ocean version (dashed), both compared with the control runs using presentday $\mathrm{CO}_{2}$, and CLIMBER-2 in the atmosphere-ocean version $A O$ (dash-dotted) and in the atmosphere-ocean-vegetation version $A O V$ (dotted), both compared with the preindustrial control run $\left({ }^{\circ} \mathrm{C}\right)$

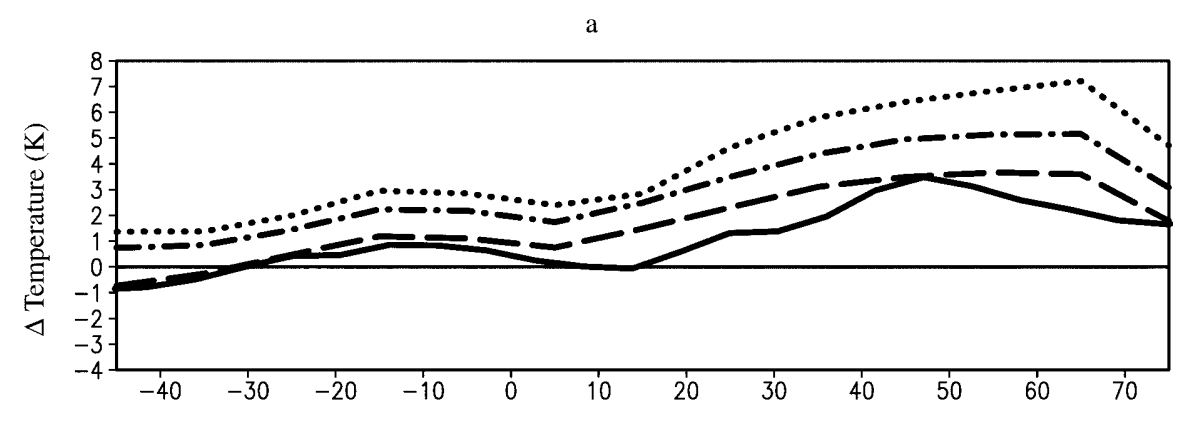

b

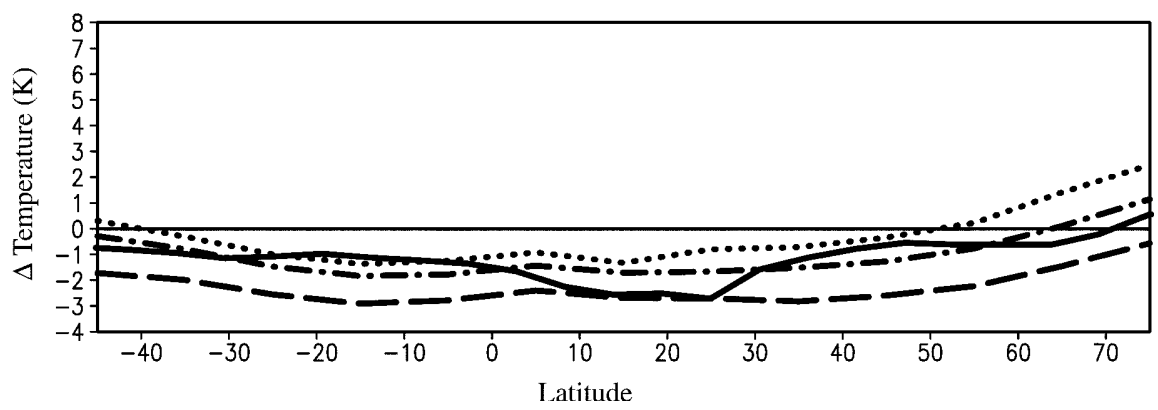

trial (instead of present-day) $\mathrm{CO}_{2}$ content for the reference simulation or allowing vegetation to interact with the changing climate, results in changes within CLIMBER-2 that are much larger than the differences from a completely different model, the ECHAM-1/LSG GCM, when run in the same configuration (Fig. 15).

Finally, the impact of the vegetation feedback yields conditions warmer than present in both hemispheres. It might well have been that those feedbacks operated during the Eemian to cause overall warmer conditions. However, a global picture of the Earth's climate for the last interglacial is as yet far from being achieved: data are scarce, mostly confined to the Northern Hemisphere, possibly resulting in interpretations of global warmth being regional biased, poorly dated and often ambiguous. This question hence remains open until additional data from the tropics or Southern Hemisphere are available.

Acknowledgements We thank Hans von Storch and Eva Bauer, as well as Colin Prentice and an anonymous reviewer for valuable comments which helped to improve this manuscript.

\section{References}

Aalbersberg G, Litt T (1998) Multiproxy climate reconstructions for the Eemian and Early Weichselian. J Quat Sci 13: 367-390

Adkins JF, Boyle EA, Keigwin L, Cortijo E (1997) Variability of the North Atlantic thermohaline circulation during the last interglacial period. Nature 390: 154-156

Bakan S, et al (1991) Climate response to smoke from the burning oil wells in Kuwait. Nature 351: 367-371

Barnola JM, Raynaud D, Korotkevich YS, Lorius C (1987) Vostok ice core provides 160000 -year record of atmospheric $\mathrm{CO}_{2}$. Nature 329: 408-414

Berger AL (1978) Long-term variations of daily insolation and Quaternary climatic changes. J Atmos Sci 35: 2362-2367
Berger A (2000) The role of $\mathrm{CO}_{2}$, sea-level and vegetation during the Milankovitch-forced glacial-interglacial cycles. In: Bengtssan L (ed) Geosphere-Biosphere Interactions and Climate. Proc Workshop held at Pontifical Academy of Sciences (in press)

Berger A, Tricot C, Gallée H, Loutre MF (1993) Water vapour, $\mathrm{CO}_{2}$ and insolation over the last glacial-interglacial cycles. Philos Trans R Soc London 341: 253-261

Borzenkova II, Zubakov VA, Lapenis AG (1992) Global climate changes during the warm epochs of the past. Meteorol Gidrol 8: 25-37 (in Russian; English translation in: Soviet Meteorology and Hydrology)

Brovkin V, Ganopolski A, Svirezhev Y (1997) A continuous climate-vegetation classification for use in climate-biosphere studies. Ecol Model 101: 251-261

Brovkin V, Ganopolski A, Claussen M, Kubatzki C, Petoukhov V (1999) Modelling climate response to historical land cover change. Glob Ecol Biogeog Lett 8: 509-517

Charney JG, Stone PH, Quirk WJ (1976) Reply. Science 191: 100-102

Cheddadi R, Mamakova K, Guiot J, de Beaulieu JL, Reille M, Andrieu V, Granoszewski W, Peyron O (1998) Was the climate of the Eemian stable? A quantitative climate reconstruction from seven European pollen records. Paleogeog, Paleoclimatol, Paleoecol 143: 73-85

Claussen M (1997) Modeling bio-geophysical feedback in the African and Indian Monsoon Region. Clim Dyn 13: 247-257

Claussen M, Gayler V (1997) The greening of the Sahara during the Mid-Holocene. Results of an interactive atmosphere-biome model. Glob Ecol Biogeog Lett 6: 369-377

Claussen M, Kubatzki C, Brovkin V, Ganopolski A, Hoelzmann P, Pachur HJ (1999) Simulation of an abrupt change in Saharan vegetation in the mid-Holocene. Geophys Res Lett 26(14): 2037-2040

CLIMAP Project Members (1984) The last interglacial ocean. Quat Res 21: 123-224

Cortijo E, Duplessy JC, Labeyrie L, Leclaire H, Duprat J, van Weering TCE (1994) Eemian cooling in the Norwegian Sea and North Atlantic Ocean preceding continental ice sheet growth. Nature 372: 446-449

Crowley TJ (1981) Temperature and circulation changes in the eastern North Atlantic during the last 150000 years: evidence from the planktonic foraminiferal record. Mar Micropaleontol 6: $97-129$ 
Crowley TJ (1990) Are there any satisfactory analogs for a future greenhouse warming? J Clim 3: 1282-1292

Crowley TJ, Kim KY (1992) Complementary roles of orbital insolation and North Atlantic deep water during Late Pleistocene interglacials. Paleoceanography 7: 521-528

Crowley TJ, Kim KY (1994) Milankovitch forcing of the last interglacial sea level. Science 265: 1566-1567

Cubasch U, Hasselmann K, Hock H, Maier-Reimer E, Mikolajewicz U, Santer BD, Sausen R (1992) Time-dependent greenhouse warming computations with a coupled oceanatmosphere model. Clim Dyn 8: 55-69

Cubasch U, Santer BD, Hellbach A, Hegerl GC, Hock H, MaierReimer E, Mikolajewicz U, Stossel A, Voss R (1994) Monte Carlo climate change forecasts with a global coupled oceanatmosphere model. Clim Dyn 10: 1-19

de Noblet N, Braconnot P, Joussaume S, Masson V (1996) Sensitivity of simulated Asian and African summer monsoons to orbitally induced variations in insolation 126, 115, and $6 \mathrm{kBP}$. Clim Dyn 12: 589-603

de Noblet N, Prentice IC, Joussaume S, Texier D, Botta A, Haxeltine A (1997) Possible role of atmosphere-biosphere interactions in triggering the last glaciation. Geophys Res Lett 23: $3191-3194$

de Noblet N, Claussen M, Prentice IC (2000) Mid-Holocene greening of the Sahara: comparing the response of two coupled atmosphere/biome models. Clim Dyn 16: 643-659

Dickinson RE, Hendersson-Sellers A, Kennedy PJ, Wilson MF (1986) Biosphere-Atmosphere Transfer Scheme (BATS) for the NCAR CCM, NCAR/TN-275-STR, National Center for Atmospheric Research, Boulder, Colorado, $69 \mathrm{pp}$

Dong B, Valdes PJ, Hall NMJ (1996) The changes of monsonal climates due to Earth's orbital perturbations and ice age boundary conditions. Paleoclimates 1: 203-240

Duplessy JC, Shackleton NJ (1985) Response of global deep-water circulation to Earth's climatic change 135000-107000 years ago. Nature 316: 500-506

Duplessy JC, Shackleton N, Matthews RK, Prell W, Ruddiman WF, Caralp M, Hendy $\mathrm{CH}(1984) \delta^{13} \mathrm{C}$ record of benthic foraminifera in the last interglacial ocean: implications for the carbon cycle and the global deep water circulation. Quat Res 21: $225-243$

Dutrieux A, Berger A, Loutre MF, Tricot C (1996) Classical feedback method and separation factor method: comparison and application to 0-D energy balance model. Progress Report 1996/3. Institut d'Astronomie et de Géophysique G. Lemaitre (ASTR), Université Catholique de Louvain (UCL), Louvainla-Neuve, Belgium

Frenzel B (1992) Climates during the Last Interglacial. In: Frenzel B, Pesci M, Velichko AA (eds) Atlas of paleoclimates and paleoenvironments of the Northern Hemisphere. Late Pleistocene - Holocene. Gustav Fischer, Stuttgart, pp 15-27, 90

Gallée H, van Ypersele JP, Fichefet T, Marsiat I, Tricot C, Berger A (1992) Simulation of the last glacial cycle by a coupled, sectorially averaged climate-ice sheet model: 2 . Response to insolation and $\mathrm{CO}_{2}$ variations. J Geophys Res 97 (D14): 15713-15740

Ganopolski A, Rahmstorf S, Petoukhov V, Claussen M (1998a) Simulation of modern and glacial climates with a coupled global model of intermediate complexity. Nature 391: 351-356

Ganopolski A, Kubatzki C, Claussen M, Brovkin V, Petoukhov V (1998b) The influence of vegetation-atmosphere-ocean interaction on climate during the mid-Holocene. Science 280: 19161919

Gates WL, Cubasch U, Meehl GA, Mitchell FB, Stouffer RJ (1993) An intercomparison of selected features of the control climates simulated by coupled ocean-atmosphere general circulation models. WCRP-82. WMO/TD-572. World Meteorological Orgnization, Geneva, Switzerland

Grichuk VP (1992) Vegetation during the Last Interglacial. In: Frenzel B, Pesci M, Velichko AA (eds) Atlas of paleoclimates and paleoenvironments of the Northern Hemisphere. Late Pleistocene - Holocene. Gustav Fischer, Stuttgart, pp 11, 85
Harrison SP, Kutzbach KE, Prentice IC, Behling PJ, Sykes MT (1995) The response of northern hemisphere extratropical climate and vegetation to orbitally induced changes in insolation during the last interglaciation. Quat Res 43: 174-184

Harvey LDD (1989) Milankovitch forcing, vegetation feedback, and North Atlantic deep-water formation. J Clim 2: 800-815

Hays JD, Imbrie J, Shackleton NJ (1976) Variations in the Earth's orbit: pacemaker of the ice ages. Science 10: 1121-1132

Hewitt CD, Mitchell JFB (1996) GCM simulations of the climate of 6 kyr BP: mean changes and interdecadal variability. J Clim 9: 3505-3529

Hewitt CD, Mitchell JFB (1998) A fully coupled GCM simulation of the climate of the mid Holocene. Geophys Res Lett 25: 361-364

Hyde WT, Crowley TJ, Kim KY, North GR (1989) Comparison of GCM and energy balance model simulations of seasonal temperature changes over the past 18000 years. J Clim 2: 864-887

Joussaume S, Braconnot P (1997) Sensitivity of paleoclimate simulations results to season definitions. J Geophys Res 102: 19431956

Jossaume S, Taylor K (1995) Status of the Paleoclimate Modeling Intercomparison Project (PMIP). In: Proc 1st AMIP Sci Conf (Monterrey, California, USA, 15-19 May 1995), WCRP-92

Jouzel J, Lorius C, Petit JR, Genthon C, Barkov NI, Kotlayakov VM, Petrov VM (1987) Vostok ice core: a continuous isotope temperature record over the last climatic cycle (160 000 years). Nature 329: 403-407

Jouzel J, Barkov NI, Barnola JM, Bender M, Chappellaz J, Genthon C, Kotlyakov VM, Lipenkov V, Lorius C, Petit JR, Raynaud D, Raisbeck G, Ritz C, Sowers T, Stievernard M, Yiou F, Yiou P (1993) Extending the Vostok ice-core record of palaeoclimate to the penultimate glacial period. Nature 364: 407-412

Keigwin L, Boyle EA (1985) Carbon isotopes in deep-sea foraminifera: precession and changes in low-latitude biomass. In: Sundquist ET, Broecker WS (eds). The carbon cycle and atmospheric $\mathrm{CO}_{2}$ natural variations Archean to present Geophys. Mono. 32: 319-328, American Geophysical Union

Kim SY, Crowley TJ, Stossel A (1998) Local orbital forcing of Antarctic climate change during the last interglacial. Science 280: 728-730

Kubatzki C, Claussen M (1998) Simulation of the global bio-geophysical interactions during the last glacial maximum. Clim Dyn 14: 461-471

Kutzbach JE, Guetter PJ (1986) The influence of changing orbital parameters and surface boundary conditions on climate simulations for the past 18000 years. J Atmos Sci 43: 1726-1759

Kutzbach JE, Liu Z (1997) Response of the African monsoon to orbital forcing and ocean feedbacks in the middle Holocene. Science 278: 440-443

Le Houérou HN (1997) Climate, flora and fauna changes in the Sahara over the past 500 million years. J Arid Environ 37: 619647

LIGA members (1991) Report of the 1st discussion group: the last interglacial in high latitudes of the Northern Hemisphere: terrestrial and marine evidence. Quat Int 10-12: 9-28

Lorenz S, Grieger B, Helbig P, Herterich K (1996) Investigating the sensitivity of the atmospheric general circulation model ECHAM3 to paleoclimatic boundary conditions. Geol Rundsch 85: $513-524$

Maier-Reimer E, Mikolajewicz U, Hasselmann K (1993) Mean circulation of the Hamburg LSG OGCM and its sensitivity to the thermohaline surface forcing. J Phys Oceanogr 23: 731-757

Manabe S, Stouffer RJ (1999) Are two modes of thermohaline circulation stable? Tellus 51 A: 400-411

Miller GH, Sejrup HP, Mangerud J, Andersen BG (1983) Amino acid ratios in Quaternary molluscs and foraminifera from western Norway: correlation, geochronology and paleotemperature estimates. Boreas 12: 107-124

Montoya M, Crowley TJ, von Storch H (1998) Temperatures at the last interglacial simulated by means of a coupled general circulation model. Paleoceanography 13: 170-177 
Montoya M, von Storch H, Crowley TJ (2000) Climate simulation for 125000 years ago with a coupled ocean-atmosphere general circulation model. J Clim 13: 1057-1072

Oppo DW, Horowitz M, Lehman S (1997) Marine core evidence for a sharp decrease in deep water production during Termination II and a relatively stable MIS 5e (Eemian). Paleoceanography 12: 51-64

Peixoto JP, Oort AH (1992) Physics of climate. American Institute of Physics, New York

Petoukhov V, Ganopolski A, Brovkin V, Claussen M, Eliseev A, Kubatzki C, Rahmstorf S (2000) CLIMBER-2: A climate model of intermediate complexity. Part I: Model description and performance for present climate. Clim Dyn 16: 1-17

Pons A, Guiot J, de Beaulieu JL, Reille M (1992) Recent contributions to the climatology of the last glacial-interglacial cycle based on french pollen sequences. Quat Sci Rev 11: 439-448

Prell WL, Kutzbach JE (1987) Monsoon variability over the last 150000 years. J Geophys Res 92: 8411-8425

Rahmstorf S (1995) Climate drift in an OGCM coupled to a simple, perfectly matched atmosphere. Clim Dyn 11: 447-458

Rahmstorf S (1996) On the freshwater forcing and transport of the Atlantic thermohaline circulation. Clim Dyn 12: 799-811

Rahmstorf S, Ganopolski A (1999) Long-term global warming scenarios computed with an efficient coupled climate model. Clim Change 43: 353-367

Roeckner E, Arpe K, Bengtsson L, Brinkop S, Duemenil L, Esch M, Kirk E, Lunkeit F, Ponater M, Rockel B, Sausen R, Schlese U, Schubert S, Windelband M (1992) Simulation of the present day climate with the ECHAM model: impact of model physics and resolution. Rep 93, Max-Planck-Institut fuer Meteorologie, Hamburg, Germany

Ruddiman WF (1985) Climate studies in ocean cores. In: Hecht AD (ed) Paleoclimate analysis and modeling. John Wiley and Sons, New York, pp 197-257
Ruddiman WF, McIntyre A (1976) Northeast Atlantic paleoclimatic changes over the past 600000 Years. Geological Society of America Memoir 145: 111-146

Sausen R, Barthel K, Hasselmann K (1988) Coupled ocean-atmosphere models with flux corrections. Clim Dyn 2: 154-163

Stein U, Alpert P (1993) Factor separation in numerical simulations. J Atmos Sci 50: 2107-2115

Stocker TF, Wright DG, Mysak LA (1992) A zonally averaged, coupled ocean-atmosphere model for paleoclimate studies. J Clim 5: 773-797

Texier D, de Noblet N, Harrison SP, Haxeltine A, Jolly D, Joussaume S, Laarif F, Prentice IC, Tarasov P (1997) Quantifying the role of biosphere-atmosphere feedbacks in climate change: Coupled model simulations for 6000 years BP and comparison with paleodata for northern Eurasia and northern Africa. Clim Dyn 13(12): 865-882

van der Hammen T, Wijmstra TA, Zagwijn WH (1971) The floral record of the late Cenozoic of Europe. In: Turekian KK (ed) The late Cenozoic glacial ages. (ed) Yale University Press, New Haven, Conn., pp 391-424

Velichko AA, Grichuk VP, Gurtovaya EE, Zelikson EM, Barash MS, Borisova OK (1992) Climates during the Last Interglacial. In: Frenzel B, Pesci M, Velichko AA (eds) Atlas of paleoclimates and paleoenvironments of the Northern Hemisphere Late Pleistocene-Holocene. Gustav Fischer, Stuttgart, pp 1325,86

von Storch JS, Kharin V, Cubasch U, Hegerl GC, Schriever D, von Storch H, Zorita E (1997) A 1260-year control integration with the coupled ECHAM1/LSG general circulation model. J Clim 10: $1525-1543$

Woillard GM (1978) Grande Pile peat bog: a continuous pollen record for the last 140000 years. Quat Res 9: 1-21

Zagwijn WH (1996) An analysis of Eemian climate in western and central Europe. Quat Sci Rev 451-469 